This manuscript is a EarthArXiv preprint and has been submitted for publication in Basin Research. Please note that the manuscript has gone through peer-review and been accepted by Basin Research with minor correction but it has not yet been formally accepted for publication. Subsequent versions of this manuscript may, thus, have slightly different content. If accepted, the final version of this manuscript will be available via the 'Peer-reviewed Publication DOI' link on the right-hand side of this webpage. Please feel free to contact any of the authors; we welcome feedback. 


\title{
Four-dimensional Variability of Composite Halokinetic Sequences
}

\author{
*Leonardo Muniz Pichel, Christopher A-L. Jackson \\ Basins Research Group (BRG), Department of Earth Science and Engineering, Imperial College \\ London, South Kensington Campus, SW7 2BP, United Kingdom \\ *email: I.muniz-pereira@imperial.ac.uk
}

\begin{abstract}
The architecture of salt diapir-flank strata (i.e. halokinetic sequences) is controlled by the interplay between volumetric diapiric flux and sediment accumulation. Halokinetic sequences consist of unconformity-bounded packages of thinned and folded strata formed by drapefolding around passive diapirs. They are described by two end-members: (i) hooks, which are characterized by narrow zones of folding $(<200 \mathrm{~m})$ and high taper angles $\left(>70^{\circ}\right)$; and (ii) wedges, typified by broad zones of folding $(300-1000 \mathrm{~m})$ and low taper angles $\left(<30^{\circ}\right)$. Hooks and wedges stack to form tabular and tapered composite halokinetic sequences (CHS), respectively. CHSs were most thoroughly described from outcrop-based studies that, although able to capture their high-resolution facies variations, are limited in describing their 4D variability. This study integrates 3D seismic data from the Precaspian Basin and restorations to examine variations in $\mathrm{CHS}$ architecture through time and space along diapirs with variable plan-form and cross-sectional geometries. The diapirs consist of curvilinear walls that vary from upright to inclined and locally display well-developed salt shoulders and/or laterally transition into rollers. CHS are highly variable in both time and space, even along a single diapir or minibasin. A single CHS can transition along a salt wall from tabular to tapered geometries. They can be downturned and exhibit rollover-synclinal geometries with thickening towards the diapir above salt shoulders. Inclined walls present a greater proportion of tapered CHSs implying an overall greater ratio between sediment accumulation and salt-rise relatively to vertical walls. In terms of vertical stacking, CHS can present a typical zonation with lower tapered, intermediate tabular and upper tapered $\mathrm{CHSs}$, but also unique patterns where the lower sequences are tabular and transition upward to tapered CHS. The study demonstrates that CHSs are more variable than previously documented, indicating a complex interplay between volumetric salt rise, diapir-flank geometry, sediment accumulation and roof dimensions.
\end{abstract}




\section{1. INTRODUCTION}

2 Salt diapirism and the associated development of minibasins are fundamental processes in salt-rich sedimentary basins. Salt diapirs can rise in response to extension, shortening and differential sedimentary loading (Vendeville and Jackson, 1992; Hudec and Jackson, 2007).

5 Passive diapirism is the syn-depositional growth of salt body at/near the free surface driven by differential vertical load of sediments within surrounding minibasins; these sediments sink into the salt-source layer, thereby pumping salt into adjacent diapirs (Nelson, 1989; Jackson and Talbot, 1991; Rowan et al., 2003; Jackson and Hudec, 2017). This mechanism drives the growth of many of the world's largest diapirs, ceasing only when salt flow is outpaced by sedimentation, typically as a consequence of depletion of the salt source-layer (Rowan et al., 2003; Jackson and Hudec, 2017).

Passive diapirism is commonly linked to the subsidence of and deposition within flanking minibasins. Minibasin deformation and associated stratal thickness variations occur at two main scales: (i) minibasin-scale, which is associated with the development of broad folds that span the minibasin width; and (ii) diapir-flank-scale, which is associated with a much narrower zone of drape folding and thinning of diapir roof strata, typically within $1 \mathrm{~km}$ of the salt-sediment interface (e.g. Vendeville and Jackson, 1991; Rowan et al., 2003; Giles and Rowan, 2012; Rowan et al., 2014). Syn-kinematic growth strata associated with diapir-flank scale deformation are referred to as halokinetic sequences (HS), which are defined as unconformitybounded packages of thinned and folded strata adjacent to passive diapirs (Giles and Lawton, 2002; Giles and Rowan, 2012; Hearon et al., 2014). Deformation of these strata is controlled by drape folding and upturn of ephemeral, thin diapir-roofs and associated flank strata during passive diapirism. Rotation and flexure are accommodated by layer-parallel slip, with little to insignificant vertical (i.e. diapir-parallel) shearing or drag fold (Giles and Rowan, 2012; Rowan et al., 2003; 2014; Hearon et al., 2014; Jackson and Hudec, 2017). 
Giles and Rowan (2012) define two end-member styles of halokinetic sequence (HS): i) hooks, characterized by narrow zones of folding $(<200 \mathrm{~m})$, high-angle truncations $\left(>70^{\circ}\right)$ beneath bounding unconformities, and abrupt facies transitions towards the salt-sediment interface; and (ii) wedges, which are typified by broad zones of folding (300-1000 m), low-angle truncations $\left(<30^{\circ}\right)$ beneath bounding unconformities, and gradual facies changes towards flanking salt (Fig. 1a). These are of parasequence scale (c. 10-50 m thick), with hooks and wedges stacking to form c. $100-1000 \mathrm{~m}$ thick tabular and tapered composite halokinetic sequences (CHS), respectively (Fig. 1b) (Giles and Rowan, 2012). Tabular CHSs have a tabular form (parallel base and top boundaries), with axial-traces within each hook sequence being offset from each other and being oriented sub-parallel to the diapir margin (Fig. 1b). They are often associated with minor salt cusps that form where the unconformities intersect the diapir (Giles and Rowan, 2012) (Fig. 1b). Tapered CHSs have a tapered shape defined by converging upper and lower boundaries, with internal axial-traces that are inclined and curve away from the diapir margin (Fig. 1b).

These halokinetic sequence end-members are thought to be a function of the interplay between local salt-rise rate $(R)$, local sediment accumulation rate $(A)$ (Giles and Rowan, 2012) and, ultimately, local diapir roof thickness (Hearon et al., 2014). In cases where diapir riserate is greater than the sediment accumulation rate $(R>A)$, hook HS will form, stacking to generate a tabular CHS. Conversely, wedge HS and tapered CHS sequences form when sediment accumulation rate outpaces diapir-rise rate $(R<A)$. In the case where $R>>A$, the diapir will flare upward and may eventually extrude an allochthonous salt sheet, whereas if $\mathrm{R}<<\mathrm{A}$, the diapir will narrow and eventually stop rising as it is buried. These sequences were first and most thoroughly described from essentially two-dimensional, outcrop-based studies (cf. Giles and Lawton, 2002; Giles and Rowan, 2012; Saura et al., 2014; Kergaravat et al., 2016; Martín-Martín et al., 2017; Moragas et al., 2018); such studies are able to capture the high-resolution facies variations occurring within relatively thin HS, at a specific structural and/or stratigraphic position, but reveal only limited information about the four-dimensional 
variability of such salt-sediment interactions. Only Hearon et al. (2014) constrain the 3D architecture and temporal variations in $\mathrm{CHSs}$, in this case using seismic reflection data from the northern Gulf of Mexico. However, they only explore a single, geometrically rather simple, plug-like diapir (i.e. stock) defined by an essentially vertical salt-sediment interface.

We here use 3D time- and depth-migrated seismic data from the SE Precaspian Basin, onshore Kazakhstan to examine vertical and lateral variability in CHS architecture along diapirs (stocks and walls) with variable planform and cross-sectional geometries. We adopt a similar approach to Hearon et al. (2014), integrating seismic data and structural restorations to analyse variations of $\mathrm{CHS}$ architecture at the present-day as well as at the time of their formation. We also use our restorations to demonstrate, for the first time, the sequential evolution of the diapirs and associated CHS strata. We focus on answering the following questions: 1) How laterally variable are CHSs along salt walls and in thick minibasin successions?; 2) What is the relationship between CHS architecture and different diapir crosssectional geometries (i.e. inclined, upright and salt shoulders)?; 3) What controls these architectural variations?; 4) How are diapir-flank and minibasin-scale deformation related?; and 5) What implications does CHS variability have for diapir-flank hydrocarbon-reservoir pinch-out?

\section{GEOLOGICAL FRAMEWORK}

The Precaspian Basin is a large $\left(540,000 \mathrm{~km}^{2}\right)$, elliptical basin located at the northern edge of the Caspian Sea in Kazakhstan and Russia, on the SE edge of the East European Craton, near the present southern margin of Eurasia (Fig. 2a-b). The basin initially formed in response to Devonian rifting and subsequent Carboniferous, post-rift thermal subsidence (Barde et al., 2002a,b; Volozh et al., 2003). The Ural Orogeny started in the middle Carboniferous in response to the collision of the eastern European and Kazakh plates, causing uplift of the Precaspian Basin's eastern side and the development of a rapidly-subsiding foreland basin in the remaining Precaspian Basin (Brunet et al., 1999; Barde et al., 2002b). During this time (i.e. 
Kungurian-Kazanian) the basin became isolated from the Tethys Ocean and a thick (up to 4.5

$\mathrm{km}$ in the basin; c. $2 \mathrm{~km}$ in the study-area) salt sequence was deposited (Barde et al., 2002b, Volozh et al., 2003; Fernandez et al., 2017). During the Upper Permian, sedimentation was dominated by westward progradation of a non-marine clastic wedge comprising material shed off the rising Ural Mountains. This wedge loaded and expelled salt westward and up into rising diapirs (Volozh et al., 2003); and resulted in development of broadly margin-parallel, $\mathrm{N}$ oriented salt walls and expulsion rollovers near the eastern basin margin (Duffy et al., 2017; Jackson et al., 2019).

Farther west and within our study-area, the salt-related structural framework is characterized by a polygonal pattern of salt walls and sub-circular minibasins (Fig. 2b), with individual walls being up to $20 \mathrm{~km}$ long, $8 \mathrm{~km}$ wide, and with up to $5.5 \mathrm{~km}$ of vertical relief (Duffy et al., 2017; Fernandez et al., 2017). Several Late Permian minibasins up to $1 \mathrm{~km}$ thick containing evaporites and non-marine clastics subsided into and are now being fully or partially encased in Lower-Middle Permian salt (Fig. 2c) (Fernandez et al., 2017). A subsequent generation of (supra-salt) minibasins formed by load-driven subsidence and passive diapirism during the Late Permian to Triassic (Duffy et al., 2017; Jackson et al., 2019). These minibasins are up to $10 \mathrm{~km}$ in diameter and up to $5.5 \mathrm{~km}$ deep, being typically welded to the pre-salt interval and/or to the encased minibasins (Duffy et al., 2017; Jackson et al., 2019). Jackson et al. (2019) show that these minibasins are characterized by lower bowl- and upper wedge-shaped units, which record periods of symmetric and asymmetric subsidence, respectively, the cause for which is unclear. Our study focusses on the geometry, stratigraphic architecture and deformation styles of diapir-flank strata within these Upper Permian-Triassic, supra-salt minibasins and their associated salt-sediment interface, which may, ultimately, help understanding the controls in the variables styles of subsidence and diapirism in the area.

The minibasins are capped by the Base Jurassic Unconformity (BJU, yellow line in fig. 2c), which records a major erosional event associated with the Late Triassic Cimmerian Orogeny. This regionally important tectonic event occurred as Gondwana-derived blocks and Tethyan 
arc fragments collided with the southern margin of Eurasia, $>1000 \mathrm{~km}$ south of the study area (Fig. 2a) (Volozh et al., 2003). Minibasins and diapirs are overlain by a gently-folded JurassicLower Cretaceous section associated with several regional, Late Cretaceous-Miocene shortening events related to the collision of Arabia and India with Asia (Volozh et al., 2003; Duffy et al., 2017). The strains associated with these pulses of shortening were relatively mild in our study area due to it lying some distance from the collision front, being mostly accommodated by squeezing of diapirs between laterally mobile, relatively undeformed suprasalt minibasins (Duffy et al., 2017; Jackson et al., 2019).

\section{METHODS AND DATASET}

\subsection{Seismic Interpretation}

We use a time-migrated 3D seismic reflection dataset that covers $2532 \mathrm{~km}^{2}$ of the eastern Precaspian Basin (Fig. 2), imaging up to 6 seconds two-way time (TWT). These data have a vertical sample rate of 2 milliseconds $(\mathrm{ms})$ and inline $(\mathrm{E}-\mathrm{W})$ and crossline $(\mathrm{N}-\mathrm{S})$ spacing of 20 m. The seismic data are presented with Society of Economic Geologists (SEG) 'normal polarity', where a downward increase in acoustic impedance is represented by a positive reflection event (white on seismic sections) and a downward decrease in acoustic impedance is represented by a negative reflection event (black on seismic sections). Our time-migrated data have better imaging of supra-salt minibasin stratigraphy than the depth-migrated volume used by Duffy et al. (2017) and Fernandez et al. (2017) to analyse the more deeply buried, encased minibasins. We therefore use these time-migrated seismic data to undertake our seismic-stratigraphic analysis of the supra-salt minibasins and halokinetic sequences, using a seismic velocity volume to perform depth-conversion of key sections. Due to its better imaging of more deeply buried structures, we use the depth-migrated data to constrain the large-scale morphology of diapirs and minibasins (e.g. top-salt depth map, fig. 3), and to test the accuracy of our depth-converted sections. 
131 Various boreholes lie within the study-area, although most are relatively shallow, terminating

132 in Upper Triassic strata. Some wells do penetrate to deeper depths, although they targeted 133 encased minibasins and, therefore, penetrate areas of thick-salt (i.e. diapirs) and do not intersect the intervening supra-salt minibasins (see Duffy et al., 2017; Fernandez et al., 2017). For this reason, we have limited control on the age and lithology of the supra-salt minibasin strata. However, given the Lower-Middle Permian age of the salt, and the stratigraphic position of the distinct Base Jurassic Unconformity (BJU), the minibasins are likely Late PermianTriassic (see above). Despite the lack of borehole data, we utilize seismic-stratigraphic relationships and geometries to define and map unconformity-bounded packages (i.e. CHS) near the diapir flanks. We present CHSs preserved within three seismically well-imaged minibasins that; i.e. because of the good to excellent image quality, we can confidently map the geometry of the salt-sediment interface and the diapir-flank stratal architecture. These minibasins are also flanked by diapirs with distinct cross-sectional styles and planform geometries, allowing us to analyse the 4D variability of CHSs associated with a range of diapir types (i.e. upright vs. inclined salt walls, salt walls vs. stocks and salt shoulders).

We mapped 16-18 CHS within each minibasin in addition to mapping base- and top-salt, and the Base-Jurassic Unconformity (BJU). The definition of $\mathrm{CHS}$ axial-traces, and the measurements of tapering angle and width of thinning, were done by estimating an inflection point where diapir-flank related tapering and thinning begin (cf. Hearon et al., 2014). Although this can be subjective, as tested here and pointed out by Hearon et al. (2014), the variance associated with picking different inflection points is insignificant $(<10 \%)$. Please note that all measurements were performed initially in the time-migrated sections and then corrected after the depth-conversions.

\subsection{Depth-Conversion and Structural Restoration}

The main criteria used to distinguish different types of seismically imaged CHS are the geometry and width of folding/stratal thinning (cf. Hearon et al., 2014). Given that these are 
both broadly sub-horizontal parameters, vertical exaggeration in our time-migrated data do not greatly affect any extracted values. However, to more accurately quantify the CHS geometries, we perform depth-conversion for each example presented here, using the seismic velocity volume mentioned above. We also perform 2D structural restorations using 2DMove@ to compare and quantify parameters such as tapering angles and folding zone width for both present and original CHS geometries, thereby eliminating distortions caused by postdepositional deformation and burial-related compaction (tables 1-3). The restoration approach and quantitative analysis are based on the method defined by Hearon et al. (2014) and utilizes the decompaction and flexural-slip unfolding algorithms (see Rowan et al., 2003; Rowan and Ratliff, 2012 for salt restoration algorithms). Vertical decompaction was done using the Sclater and Christie (1980) compaction function for sand and shale, which is appropriate given the known composition of the suprasalt minibasins.

\section{COMPOSITE HALOKINETIC SEQUENCE VARIABILITY}

Suprasalt minibasins formed during the Upper Permian-Triassic in response to differential loading and passive diapirism (see Jackson et al., 2019). In many of these minibasins, CHSs are not visible due to: i) minibasin tilting and associated rotation of near-flank strata to nearvertical due to late-stage shortening and diapir squeezing (Duffy et al., 2017) and/or ii) the presence of large salt overhangs, which hampers imaging of the sub-diapir flank strata. We thus focus our analysis of CHS geometry on two distinctly different diapir geometries observed around three minibasins: 1) an inclined-diapir margin (Fig. 4a), and 2) a vertical salt wall that passes along-strike into a salt roller (Fig. 4b). We first describe how the CHSs vary vertically in individual cross-sections before assessing how they vary laterally by comparing multiple cross-sections and 3D images.

Inclined diapir flanks (Fig 4a and left-hand side of fig. 4b) afford excellent imaging and highconfidence interpretation of the salt-sediment interface and, consequently, of CHS tapering and width of thinning. Where diapir flanks dip more steeply (e.g. Fig. 4b, right-hand side), the 
precise definition of the salt-sediment interface can be, in places, problematic. In these cases, the interpreted diapir flank may be slightly $(20-30 \mathrm{~m}$ ) offset from its true position (Fig. 4). The distinction between different CHS end-members is therefore based primarily on the shape of the sequence (i.e. degree of upturning and parallel vs. convergent bounding surfaces) and secondarily on the width of folding on both present and restored sections (see section 4.2.2).

In all examples, the CHS are bounded by pronounced erosional unconformities that extend < $1 \mathrm{~km}$ away from the diapir margin, passing into correlative unconformities towards the minibasin centre (Fig. 4). The CHS are upturned and are in direct contact with the diapir, and have variable degree of folding, thinning, and structural relief (Fig. 4, tables 1-3). Where the salt-sediment interface dips gently and the diapir-flank seismic imaging is best, we also observe minor salt cusps where bounding unconformities intersect the diapir; these are especially prominent in tabular CHS (Fig. 4a). In general, the CHS present multiple internal unconformities associated with higher-order halokinetic sequences (cf. Giles and Rowan, 2012) and display basal onlaps at or near their axial-traces (Fig. 4). In other cases, especially within tabular CHS, low-continuity-to-chaotic facies interfinger with more continuous, brighter reflections near the diapir-margin, possibly indicating debris flows sourced by material eroded from the diapir's crest (Fig. 4). In this study, we also define 'transitional' CHSs; these have geometries and widths of folding that are intermediate (i.e. 200-300 m) between tabular and tapered end-members (Fig. 4), although in most cases their shape more closely resembles that of the tabular end-members (see restored sections, section 4.2).4.1. Inclined Diapir

\subsubsection{Overall geometry}

In our first example, we analyse the CHS architecture on the southwest flank of a semi-circular minibasin associated with a c. $12 \mathrm{~km}$ long curvilinear salt wall that has an inclined flank $\left(40^{\circ}\right.$ in its lower section increasing to $60^{\circ}$ in its upper section; figs. 5-7). The minibasin tilts to the SW due to shortening-induced uplift of its NE flank; in contrast, the southwest wall and associated CHS strata, which form the focus of our analysis, are largely undeformed. This 
tilting made the dip of the southwest salt wall even gentler, meaning we can more confidently define the salt-sediment interface, and related CHS stratigraphic architecture, than in previous studies focused on very steep-sided salt diapirs (Fig. 4a) (cf. Hearon et al., 2014).

\subsubsection{Minibasin and $\mathrm{CHS}$ architecture}

The first stage of diapir growth was controlled by minibasin-scale subsidence as evidenced by a lower bowl-shaped stratigraphic section with a sub-vertical, synclinal axial-trace at its centre (Figs. 5-6) (cf. Rowan and Weimer, 1998; Jackson et al., 2019). The second stage was characterized by a switch in the location of depocentres towards the flank of the diapir as indicated by the large-scale wedge geometry associated with at least $16 \mathrm{CHS}$ observed in profiles sub-parallel to the wedge dip-direction (Figs. 5-6). The inclined wall is flanked largely by tapered CHS (Figs. 5-6), with only two (northern section, fig. 5) and one CHS (central section, fig. 6) out of the 16 being classified as tabular (table 1).

In general, tabular CHS are relatively thinner (150-250 m at present, fig. 8 and 180-300 m decompacted, fig. 9) than tapered CHSs (150-450 $\mathrm{m}$ at present, fig. 8 and 180-520 m decompacted, fig. 9) and occur towards the intermediate-to-late stages of diapir rise and minibasin subsidence (i.e. in the middle and uppermost parts of the minibasin; CHSs 13-14, fig. 5 and CHS 13, fig. 6). Tabular CHS have folding and thinning zones ranging from 90-185 $\mathrm{m}$ of width (100-200 $\mathrm{m}$ restored) and taper angles of $60-64^{\circ}\left(54-60^{\circ}\right.$ restored, Table 1$)$, values that are relatively low when compared to tabular $\mathrm{CHS}$ associated with the upright wall (see section 4.2.). The tapered CHS have a folding and thinning zone ranging from 360-940m (420$1000 \mathrm{~m}$ restored) and taper angles of $8-44^{\circ}\left(12-35^{\circ}\right.$ restored).

The minibasin and individual CHS become, in general, thinner southwards, with this being associated with a switch from dominantly tapered (Figs. 5-6), to a mixture of tabular and tapered CHSs (Fig. 7, table 1). CHS end-member distribution is also notably different in the south, with tabular CHS occurring in the lower and uppermost sections, and being separated by an intermediate section with tapered CHS (Fig. 7). The lower CHSs (1-6), which have 
typical tapered geometries in the northern and centrals sections (Figs. 5-6), have, in the south, a narrow $(<100 \mathrm{~m})$ zone of folding and thinning towards the diapir, with prominent salt cusps intercepting their unconformities (Fig. 7, table 1) (cf. Giles and Rowan, 2012; Hearon et al. 2014). These CHS also become condensed to the south, being only c. 80-100 m thick (fig. 7), which is equivalent to the thicknesses of higher-order, halokinetic sequences (Giles and Rowan, 2012). CHS 14-16, despite maintaining their thickness, also switch southwards from tapered to tabular (Fig. 5-7, table 1).

The lowermost CHSs (1-4, table 1) present more unique lateral variations, demonstrating the increasing influence of larger, minibasin-scale folding and subsidence towards the centre of the salt wall (Figs. 5-6). Although, their geometries are indicative of diapir-flank processes, i.e. their thinning and folding still occurs near the diapir margin, the width of the folding zone increases up to $2100 \mathrm{~m}$ away from the diapir and taper angles are considerably lower $\left(11-14^{\circ}\right.$ restored, table 1, fig. 8).

\subsubsection{Diapir and Minibasin Evolution}

The dominance of tapered CHSs in the inclined diapir example suggests that the development of gently-inclined salt walls is associated with a predominantly higher sediment accumulation rate $(A)$ relative to the net salt-rise rate $(R)$ (and/or volumetric salt flux (q); cf. Jackson and Hudec, 2017) (Figs. 5-6 and 8-9). This interpretation is supported by the fact that the wall exhibits a subtle steepening of its margin through time (from c. 40 to $60^{\circ}$ ) that correlates with a general upward narrowing of the zone of folding and thinning of minibasin strata (Table 1 and fig. 9), which, in turn, implies a relative increase of $R / A$ or $q / A$.

The CHS geometries and distribution are also variable along-strike as shown by the greater proportion of tabular CHS geometries to the south (Fig. 7), where the salt wall is also steeper (Figs. 5-7). This southward transition from tapered to tabular CHS geometries may be associated with: i) significant thinning of individual CHS (e.g. CHS 1-5) and, thus, a lateral decrease in the sediment accumulation rate that resulted in increase in $R / A$ or $q / A$; or ii) along- 
strike variations in diapir-rise rate $(\mathrm{R}$ or $\mathrm{q})$ in the cases where CHS thickness does not vary along-strike (e.g. CHS 14-16). The latter may thus be better explained by volumetric (i.e. 3D) salt flux variations and local variations of roof thickness and width, rather than the classical two-dimensional A/R ratios (cf. Giles and Rowan, 2012) (see discussion).

\subsection{Vertical salt wall}

\subsubsection{Overall Geometry}

Our second example comes from two adjacent minibasins flanking a 3-4 km tall, $3 \mathrm{~km}$ long and 1-2 km wide, N-trending salt wall (Fig. 3). The diapir is upright and has a sub-vertical upper flank and a more gently-dipping lower flank (Fig. 10). It varies in shape and dimension along-strike, passing northwards into a smaller diapir containing a $1.5 \mathrm{~km}$ wide salt shoulder (sensu Giles et al. 2018) half-way up its western flank (Fig. 11), and ultimately into a salt roller (sensu Vendeville and Jackson, 1992a) at its northern end (Fig. 12). Because the two minibasins are connected around the diapir and roller at their northern end, it is possible to constrain the relative ages of CHSs on both sides of the diapir (Figs. 4-6.). This provides a unique opportunity to analyse how: i) a single CHS can vary across a salt wall with laterally variable cross-sectional geometry, ii) how two minibasins associated with the same salt wall can have variable $\mathrm{CHS}$ architecture, and iii) how CHSs transition from halokinetically-driven diapirs (passive and/or active) to diapirs driven by extension (i.e. reactive).

\subsubsection{Minibasin and $\mathrm{CHS}$ architecture}

The diapir is flanked on both sides by CHS (Figs. 10-11). Both minibasins contain a lower, 1$1.5 \mathrm{~km}$ thick, bowl-shaped section, which is c. $400 \mathrm{~m}$ thicker in the western minibasin than in the eastern minibasin (Fig. 10). This section thins northwards, towards the edge of the salt diapir, with age-equivalent strata showing typical CHS geometries (i.e. narrow zones of folding and thinning). The overlying stratigraphic succession is composed of strata that are of broadly constant thickness (on average 90-320 m thick at present-day) towards the minibasin centre, 
but which display localized $(<1 \mathrm{~km})$ thinning and folding near the salt-sediment interface, characteristic of CHSs (tapered and tabular) (Figs. 10-11).

There are drastic variations in the geometry and distribution of CHSs between the two partiallyconnected minibasins (Figs. 10-11). In Section 1, the western minibasin is dominated by tapered CHSs from the earliest-to-intermediate (CHSs 1-12) to final stages of diapir growth (CHSs 17-18), with only four non-tabular (e.g. tapered and transitional) CHSs in the intermediate-upper section (CHSs 13-16, fig. 10, table 2). The tapered CHSs are characterized by thinning and folding zones ranging from 370-1970 m (350-1180 m restored) with an average of $830 \mathrm{~m}$ (720 m restored), and taper angles of $13-49^{\circ}\left(11-30^{\circ}\right.$ restored), with an average of $31^{\circ}\left(18^{\circ}\right.$ restored) (Table 2$)$. The tabular $\mathrm{CHSs}$ have folding zones ranging from 45-190 m (30-155 m restored) with an average of $100 \mathrm{~m}$ (present-day and restored) and taper angles of $52-74^{\circ}\left(50-72^{\circ}\right.$ restored), with an average of $64^{\circ}\left(60^{\circ}\right.$ restored) (Table 2). Conversely, the eastern minibasin is dominated by tabular rather than tapered CHSs, with only two tapered (CHS 2 and 10) and two transitional CHSs (CHS 1 and 5). The two tapered CHS have thinning and folding zones ranging from 300-810 $\mathrm{m}$ (310-915 $\mathrm{m}$ restored) and taper angles of $18-26^{\circ}\left(17-18^{\circ}\right.$ restored) (Table 2$)$. The tabular CHS have folding zones varying from 45-190 m (45-170 m restored) with an average of $96 \mathrm{~m}$ (109 m restored), and with taper angles of $40-71^{\circ}\left(36-68^{\circ}\right.$ restored), with an average of $57^{\circ}\left(52^{\circ}\right.$ restored) (table 2$)$.

Only CHSs 2, 10 and 14-16 have the same end-member geometries across the diapir; they do however differ in terms of their width and taper angle (Table 2). They also differ in terms of their thickness, with CHSs being generally thicker on the western, tapered CHS-dominated minibasin (Figs. 10 and 13a). The largest thicknesses contrasts occur within CHSs 3-7, which are tapered and up to $320 \mathrm{~m}$ thick on the west minibasin, and tabular and only 90-150 m thick in the east minibasin (Fig. 13a). This CHS variability can be linked to changes in the diapir flank morphology (Fig. 4). The lower-to-intermediate diapir section (between CHSs 1-5) has a more gently-dipping (c. $40-50^{\circ}$ ) flank, with a series of narrow (c. 300-500 m), sub-horizontal $\left(15-30^{\circ}\right)$ salt shoulders on the west where tapered CHSs predominate (Fig. 10). Conversely, 
313 the equivalent, lower-to-intermediate eastern diapir flank is steeper $\left(55-65^{\circ}\right)$, has no

314 recognizable salt shoulder and is largely associated with tabular CHSs (Fig. 10). The upper 315 diapir flanks are sub-vertical (c. $\left.90^{\circ}\right)$ on both sides and predominantly associated with tabular 316 CHSs (CHSs 13-16) in both minibasins, although the final two (CHS 17-18) are characterised 317 by tapered and tabular geometries on the west and east minibasin section, respectively (Fig. 318 4).

Section 2, another dip-oriented section located $1.2 \mathrm{~km}$ further north of Section A, demonstrates how CHS and diapir geometries vary significantly over a relatively short along-strike distance (Fig. 11, table 3). In this location the salt wall is shorter (c. $2.8 \mathrm{~km}$ tall) and is defined by a broader (1.5 km wide), clearly-defined salt shoulder relative to Section A (Fig. 10). Strata ageequivalent to CHSs 13-18 from Section A (Fig. 10) are not classified as CHS because they cover the diapir and show no diapir-related thickness variations (Fig. 11). The tabular CHSs, all in the western minibasin, have present folding zones varying from 20-200 m (average of $93 \mathrm{~m}$ ) and taper angles from $42-86^{\circ}$ (average of $65^{\circ}$ ) (Fig. 11, table 3). The tapered CHSs have a 325-1100 m wide zone of folding (average of $480 \mathrm{~m}$ ) and are defined by tapers angles of $11-49^{\circ}$ (average of $30^{\circ}$ ) (Fig. 11 , table 3 ).

The eastern minibasin in Section 2 shows a similar distribution of CHSs to that seen in Section A (Fig. 10), but with a significantly greater proportion of tabular geometries (i.e. all but the last CHS are tabular; Fig. 11, table 3). The western minibasin, however, exhibits more marked along-strike variations; it has no tabular CHSs and contains CHSs (2-5) that are downturned and thickened towards the diapir (Fig. 11). The restored geometries indicate $10-15 \%$ of localized stratal thickening into the axes of near-diapir synclines or rollovers above the salt shoulders (Fig. 13b). All other CHSs (1 and 6-12) are tapered. CHSs 2-5 thus differ to previously described CHSs given they are rotated downward and thicken into a near-diapir rollover; ultimate thinning towards the diapir simply reflects stratigraphic onlap onto the inclined salt-sediment interface, rather near-diapir upturn (see Fig. 1, Giles and Rowan, 2012). They are, nonetheless associated with classic tapered CHS geometries and diapir flank- 
related deformation $1 \mathrm{~km}$ further south, i.e. thickness variations and folding occur within 370$680 \mathrm{~m}$ from the salt-sediment interface. The kinematics of this different style of CHS with the synclinal-rollover geometry over an area of pronounced narrowing of the diapir (i.e. salt shoulder) will be addressed in Section 5.2 .

$1.2 \mathrm{~km}$ further northward (Section 3), the salt-related structural style changes from a diapir to that of a normal fault-bound salt roller nucleating onto gently inflated salt (Figs.10-12). The upper salt roller is defined by an east-dipping listric normal fault that is overlain by a westverging extensional rollover. The age-equivalent stratal architecture seen here is notably different from that seen further south. More specifically, minibasins strata do not display typical CHS geometries (i.e. diapir flank upturning and thinning). Instead, sequences 1-10 are all downturned towards the roller on both of its sides, with sequences on the eastern side also thickening towards the roller-bounding fault (Fig. 12). Strata are broadly isopachous on the footwall, although subtle thinning occurs between sequences 1-3, which onlap the earlier diapir. Sequences 1-3 may thus be classified as tapered CHS that were later collapsed and downturned due to extension (Fig. 12).

The unique along-strike variations in CHS architecture and diapir morphology described above are best visualized in 3D (Fig. 14). This 3D image shows how a single CHS transitions from: i) a tabular geometry with abrupt thinning towards the diapir eastern flank to, ii) localized downturn above a salt shoulder to the northwest, and to, iii) a tapered geometry that extends $350 \mathrm{~m}$ upward along the western diapir flank (Fig. 14). Northwards, towards the axis of the larger depocentre, the CHS gives way to fault-related hangingwall thickening towards a rollerbounding normal fault, until it switches again to typical CHS geometries associated with a different salt wall further north (Fig. 14).

\subsubsection{Diapir and Minibasin Evolution}

Sequential structural restorations illustrate the evolution of the salt wall and associated growth strata, helping explain the observed CHS variability along the two, partially-connected 
minibasins (Figs. 15 and 16, supplementary material). The restoration demonstrates that the diapir grew passively and asymmetrically since its earlier stages, with a gentler western flank and steeper eastern flank (Figs. 15-16). This style of growth is recorded in the CHS architecture; i.e. the development of tapered CHSs on the gently-dipping, western flank and tabular CHS on the more steeply-dipping, eastern flank. Moreover, the restorations also show that the coeval development of different CHS end-members on each side of the diapir is associated with how far syn-kinematic strata extends across the diapir flank and/or onto its crest (Fig. 15). The CHS therefore formed as temporary roofs that were shouldered aside and upturned due to continuous salt rise (cf. Rowan et al., 2003) (Figs. 15-16).

The restorations also show how the development of tapered geometries that extend 200-350 $\mathrm{m}$ along the western flank of the diapir (CHSs 1-9) is related to the occurrence of salt shoulders. These narrow shoulders are partially destroyed due to continuous salt rise, which also reduces the diapir asymmetry and overall width, and further rotates previously-deposited CHSs (Fig. 15). Some of these early tapered CHSs formed small-scale anticline-syncline pairs along the flank of the diapir as they onlapped supra-shoulder strata and/or the shoulder itself (CHSs 2-4, fig. 15, supplementary material). These units may record brief episodes of relatively minor shoulder-collapse due to dissolution and/or salt expulsion (cf. Giles et al., 2018). The width of the salt shoulders varied along-strike (Figs. 15 and 16). Where it formed a km-scale feature, supra-shoulder strata collapsed and downturned above it, forming a rollover with localized thickening towards the diapir (CHSs 2-5, fig. 16).

\section{DISCUSSION}

\subsection{How laterally and vertically variable are Composite Halokinetic Sequences?}

Our study confirms the hypothesis of Hearon et al. (2014) that different CHS end-members can form along the same diapir at the same time. However, we demonstrate that CHSs can vary even more drastically and frequently across salt diapirs than previously described. All CHSs analysed here have laterally variable drape-fold widths, taper angles and relief (Figs. 5- 
7, 10-11 and Tables 1-3). This corresponds to an overall greater lateral variability than observed by Hearon et al. (2014), where only three CHSs (<10\% of the total number analysed) varied along-strike. These variations can be relatively subtle so that the $\mathrm{CHS}$ end-member does not change. In many cases, however, CHSs can vary from one end-member to another within the same minibasin and over only $<1 \mathrm{~km}$ along strike (Figs. 5-7 and 10-11, tables 1-3). A single $\mathrm{CHS}$ can also vary between tabular and tapered end-member geometries along-strike and across the same diapir, and within two different, albeit partially-connected minibasins (Figs. 10-11, tables 2-3). CHS relief can also change significantly (c. 100-300 m) along an individual CHS, especially in the case of tapered end-members that can have up to $400 \mathrm{~m}$ of structural relief (cf. CHSs 5 and 7-11, figs. 6; CHSs 4, 6 and 8, fig. 10).

These sequences can also transition laterally, over very short length-scales (c. $1 \mathrm{~km}$ ), from classical CHS (i.e. locally upturned and thinned) into rollover CHSs with localized stratal thickening above salt shoulders, fig. 11). They can also switch laterally into normal-fault-driven thickened strata overlying salt rollers, or even into isopachous and relative undeformed strata away from the diapir and, thus, not being classified as CHSs (Figs. 11-12). These sequences can also transition along-strike from being controlled by diapir-flank scale deformation, to being influenced and even driven by minibasin-scale subsidence towards their centre (cf. Rowan et al., 2016). Such transitions are more common within deeper, older CHSs (Figs. 5-6 and table 1 , see section 5.4).

The classic CHS succession consists of lower tapered, intermediate tabular, and upper tapered CHSs (Giles and Rowan, 2012; Hearon et al., 2014). The stratigraphic transition from lower tapered CHSs to tabular CHSs is associated with an increase in the rate of salt-rise as the minibasin gradually thickens, becomes denser, and pumps salt more rapidly into the flanking diapirs. As a continuum of this process, the source-layer is gradually depleted, resulting in a decrease in the salt-rise rate and, as a consequence, a switch from tabular to tapered CHSs (Giles and Rowan, 2012). Our work shows that switches from tabular to tapered end-members can be more frequent than previously documented (Table 2). These switches 
are commonly linked to marked changes in diapir shape, such as those occurring in association with salt shoulders (Figs. 10-11 and 15-16) (see section 5.2). Moreover, the CHS succession can also display vertical patterns that differ to the classical three-part vertical zonation (Figs. 7 and 10-11, tables 1-3). For example, the vertical wall is flanked on the east by a minibasin dominated by tabular CHS (Fig. 10, table 3). In contrast, the minibasin to the west is defined by the classic tapered-tabular-tapered vertical zonation (Fig. 10, table 3). The inclined wall displays a more typical zonation along most of its length, having a dominantly tapered CHS succession, with only a few tabular CHSs towards its top. However, towards the south, this zonation is different, with the lower and uppermost sections being composed of tabular CHSs with intermediate tapered CHSs (Fig. 7, table 1).

\subsection{What is the interplay between different diapir cross-sectional geometries and CHS} architecture?

\subsubsection{Geometrical variations between different diapirs}

This study provides the first-ever analysis of CHS architecture adjacent to diapirs with differing flank geometries. Diapirs with sub-vertical margins are flanked a greater proportion of tabular CHSs (27\% on west minibasin to $78 \%$ on east minibasin) relative to inclined diapirs $(8-50 \%)$. This suggests that, for diapirs with sub-vertical flanks and at a CHS time-scale, diapir-rise rate is generally greater than sediment accumulation rate when compared to inclined diapirs. This example also shows that even broadly symmetric diapirs can be flanked by minibasins with highly-asymmetric stratigraphic architectures. Age-equivalent strata on both sides of the diapir display, in most cases, contrasting end-member CHS geometries and up to $80-100 \%$ of thickness variations (Figs. 10-11, 13 and tables 2-3). Such asymmetric subsidence (Figs. 1516) can be related to three-dimensionally complex patterns of salt flow and diapir rise (Jackson et al., 2019; Fernandez et al. 2019).

The example of a diapiric wall with an inclined margin shows that, in addition to a generally greater proportion of tapered CHSs, the ratio of tapered CHS (to tabular or transitional CHSs) 
445 is higher towards their centre (Figs. 5-7 and table 1). The width of the folding/thinning zone 446 commonly increases, and taper angles of tapered CHSs typically decreases, towards the 447 centre of the wall (CHSs 7-16, table 1; although see CHSs 17-19 in table 1 for an exception). Ultimately, this demonstrates laterally variable diapir-rise rate and minibasin subsidence through time (cf. Jackson et al., 2019; Fernandez et al., 2019). The gently-dipping diapir margin and the related architecture of the flank strata suggest that in the case of inclined walls, sediment accumulation-rate tends to be greater than diapir-rise rate, which is the opposite to that inferred for vertical walls. As salt diapirs typically grow vertically when salt-flow rates equal sediment aggradation rates (Vendeville and Jackson, 1991; McGuiness and Hossack, 1993), sedimentation accumulation rate is expected to be slightly higher than salt-rise rate at $\mathrm{CHS}$ time-scales for inclined diapirs. Nonetheless, at a longer, minibasin-time-scale, salt rise can still keep pace with sedimentation as evidenced by continuous salt rise. The initial rise of inclined walls is dominated by minibasin-scale subsidence and deformation as indicated by the presence of an up to $2.5 \mathrm{~km}$ thick bowl-shaped lower sequence (Fig. 6); this contrasts with the vertical walls, for which we infer a shorter period of minibasin-scale subsidence based on the presence of a significantly thinner (c. 200-500 m) bowl-shaped lower interval (Figs. 1011).

\subsubsection{Salt Shoulders}

Salt shoulders are zones of abrupt diapir narrowing due to differential salt-rise from the diapir margin to its centre as a function of salt supply, dissolution and roof thickness (Giles et al., 2018). We recognise salt shoulders in our study-area, with the related stratal architecture and transition patterns between non-shoulder and shoulder-related strata being characterized by: i) a switch from tabular CHS to tapered CHS, ii) a marked increase in the width of folding and thinning of tapered CHSs, and iii) rollovers within which strata dip in towards and thicken into the hinges of near-diapir flank synclines. The simpler scenario (i) is the abrupt change between tabular and tapered CHS end-members occurs over a narrowing salt-sediment interface (Fig. 17, CHS 3-4). In this case, there is a drastic increase in the width of folding, from c. $100 \mathrm{~m}$ 
below to $650 \mathrm{~m}$ above the shoulder and over the erosional unconformity defining the top of a series of tabular CHSs (Fig. 17). In the second case (ii), similar increases in the width of the folding and thinning zone occur without changes to a different $\mathrm{CHS}$ end-member. This is seen along the western flank of the vertical wall by a pronounced lengthening (in the order of 170$300 \mathrm{~m}$ ) of the zone of folding between tapered CHSs 4 and 5, 5 and 6, and 6 and 7 (Figs. 10 and 15 , table 2).

The third shoulder scenario (iii) presents a more complex and remarkable supra-shoulder stratal architecture. In this case, pre-shoulder CHSs transition upwards over the shoulder into downturned and folded sequences that thicken towards the diapir (CHSs 2-5, Fig. 11). Their characteristic rollover and synclinal thickening geometries may suggest: i) salt expulsion from the shoulder towards the central part of the diapir, ii) an extension-driven faulted-contact, or iii) shoulder collapse due to dissolution (Giles et al., 2018). Although the third option seems more likely, our current knowledge and limited published data on salt shoulders (cf. Giles et al., 2018) do now afford a distinction between these three processes.

\subsection{What controls CHS variations?}

Different CHS end-members are likely a function of the relative rates of salt-rise $(R)$ and sediment accumulation (A) (Giles and Rowan, 2012) or, more precisely, local diapir-roof thickness (Hearon et al., 2014). We concur with these hypotheses, but we add that diapir rise and sediment accumulation rates (and thus roof thickness) can vary along and across diapirs. We argue below that this variability may be ultimately driven by three-dimensional variations in the rate of diapir-rise (i.e. volumetric salt flux), something not depicted in previous $\mathrm{CHS}$ models (Fig. 18).

Variable sediment accumulation and volumetric salt flux generate thickness variations within individual CHSs (Figs. 5-8, 10-13). These variations may be a function of the direction of sediment input into the minibasin, and differential erosion and/or subsidence around the diapir flank and on its crest. Indeed, local sediment input direction and accumulation may have 
influenced roof thickness in the case of the two partially-connected minibasins separated by a vertical salt wall, as suggested by pronounced changes (by up to 100\%) in CHSs thickness around the wall (see restored CHSs 4 and 7, fig. 13). Consequently, the CHS end-member type varies for age-equivalent strata across the diapir with thicker tapered geometries on one side and thinner tabular geometries on the other (Figs. 10-11 and tables 2-3). This is expected given that tapered CHSs are typically associated with relatively higher sediment accumulation rates than tabular CHSs (Giles and Rowan, 2012). Overall minibasin thickness and subsidence are logically also greater where CHS are dominantly tapered and thicker, i.e. the western minibasin in Figs. 10 and 11.

However, this is not consistently observed within all age-equivalent $\mathrm{CHSs}$, nor for the inclined wall case as CHS architecture also varies regardless of overall thickness (e.g. CHSs 8-9 and 11, with equal thickness and different end-member geometries, fig. 13). This suggests that something else, in addition to sediment accumulation rate, controls CHS style. We argue that the near-diapir thickness variations characteristic of CHSs are controlled by how far the related strata extended inboard above the flanking diapirs, and that this is potentially governed by the three-dimensionally variable salt flux (q) within the diapir. This is seen in our restorations where CHSs of broadly equal thickness across the diapir are characterized by distinct taper angles and drape-fold widths, principally because of how far they originally extended across the diapir crest (CHSs, 8-9 and 11, Figs. 15, 18 and supplementary material). Consequently, tapered CHSs are commonly associated with gentler and wider diapir margins than tabular CHSs. Progressive diapir rise, nonetheless, displaces and rotates the CHS salt-sediment interfaces from an initially crestal position to the sides of the diapir, partially masking their original shape and extent (Figs. 9,15 and 16). In addition, erosion may also remove parts of or, in fact, the entire diapir roof so that CHS may have extended further across the diapir crest than is currently inferred from the size and geometry of the preserved wedges.

Restorations also demonstrate that tapered CHS can occur over transient salt shoulders that record a period of diapir narrowing. We note that this may occur on only one flank of the diapir 
525 (Fig. 15). Tapered CHS that extend for $>200 \mathrm{~m}$ along the present-day flank of the diapir (Figs.

$5266,9,10$ and 11) were originally formed over transient salt shoulders. These salt shoulders

527 may be preserved depending on the degree of subsequent diapirism and differential diapir-

528 rise. We thus suggest that, in addition to i) diapir-flank dissolution-collapse, ii) greater roof

529 erosion at the diapir centre and iii) fault-related weakening of the central roof (cf. Giles et al., 530 2018), salt shoulders can also develop due to: iv) roof thickness variations associated with tapered CHSs that extend further inboard over the diapir.

\subsection{How CHSs interact with minibasin-scale subsidence?}

533 At early stages of diapir rise and minibasin formation, subsidence is dominantly accommodated by broad, multi-km-scale synclinal folding, and stratal thinning and onlap towards the diapir (i.e. bowl-shaped minibasins, Figs. 5-6 and 10). In later stages, subsidence tends to be more evenly distributed across the minibasin, with deformation focused near the diapir margin, resulting in the development of stacked halokinetic sequences (Giles and Rowan, 2012; Hearon et al., 2014). Our restorations show that, although primarily controlled by diapir-flank processes, CHS typically display subtle thickness variations (c. $5-15 \%$ of their maximum thickness) over a much larger (> $1 \mathrm{~km}$ of width) scale (Figs. 8 and 13).

The influence of minibasin-scale processes on CHS geometry is variable in time and space. It is typically greater within lower sequences (CHS 1-3 in fig. 5-6; CHSs 1-4 in fig. 10), immediately after the bowl-shaped sequence, which indicates a transitional period in which subsidence and deformation are roughly equally influenced by diapir-margin and minibasin processes. As a consequence, the definition of $\mathrm{CHS}$ axial-trace for the lowermost sequences can be complicated by the greater influence of larger wavelength, and minibasin-scale folding and thinning. Minibasin-scale subsidence is also more important towards the central portions of linear salt walls where lowermost sequences are controlled by minibasin-scale processes, passing laterally towards their edges into CHSs (CHSs 1-2, figs. 5 and 6, table 3). Ultimately, 
550 this demonstrates that diapir-flank and minibasin-scale deformation work in tandem and, in

551 most cases, as a continuum process.

552

553

554

\subsection{Implications for hydrocarbon reservoirs}

The recognition of km-scale, four-dimensional variability of $\mathrm{HS}$ and $\mathrm{CHS}$ has implications for the understanding of potential hydrocarbon reservoir distribution within minibasins and the development of diapir-flank stratigraphic (i.e. pinch-out) traps. Reservoir sandstones deposited in channels and lobes will tend to accumulate downdip of diapir-related topographic relief (Matthews et al., 2007; Banham and Mountney, 2013; Hearon et al., 2014). This means that reservoirs will pinch-out updip, at or near the axial traces of drape folds developed within CHSs (Fig. 4) (Giles and Rowan, 2012; Hearon et al., 2014). Tabular CHS may, therefore, have reservoir facies that are in direct contact with the diapir or that pinch-out less than 200 m away from it. In contrast, tapered CHS may contain reservoirs that pinch-out 300-1000 m away from the diapir (Fig. 4). As CHSs vary along-strike and across salt walls, reservoir distribution and pinch-out will also vary. The same CHS may have reservoir facies in direct contact with the salt wall on one side and $>300 \mathrm{~m}$ away from the diapir on its other side (Fig. 18). Although our work focuses on fluvial-continental and clastic-dominated minibasins, the observed geometric variability of diapir-flank strata can also be applied to shallow- and deepwaters settings influenced by diapirism and, ultimately aid the prediction of reservoir-facies and pinch-out location within minibasins.

\section{CONCLUSIONS}

This study combines 3D seismic and 2D structural restorations to analyse the interaction between diapirism with minibasin subsidence and deformation, focusing on diapir-flank architecture and development of composite halokinetic sequences. We provide for the first time, a 3D, seismic-based study that evaluates the development of composite halokinetic sequences associated with different geometries and styles of diapirs, demonstrating that CHSs can be highly variable through time and space. We analyse CHS variability within a 
576 single minibasins along an inclined salt wall; and within two different minibasins across an

577 upright, broadly vertical salt wall. A single CHS can vary along-strike within the same minibasin

578 and across a diapir. Their large majority (c. 73\%) varies laterally across a salt wall, presenting contrasting end-member (i.e. tabular or tapered) geometries. They can also transition into isopachous and broadly undeformed strata away from the diapir or to growth strata associated with salt-related extension or diapir-collapse (i.e. rollovers). These lateral variations can be linked to changes in CHS thickness and/or in the diapir flank geometries. Tabular CHSs are commonly associated with steeper diapir flanks and tapered CHSs with relatively gentler saltsediment interfaces. CHSs can also be more vertically variable than previously described, presenting more frequent switches in their geometries through the stratigraphic succession or different vertical zonations to the classic CHS models. These are often associated with changes in diapir geometry such as salt shoulders, which are characterized by an abrupt narrowing and gentling of the salt-sediment interface. These features are typically associated with a marked increase in the width of folding between pre- and post-shoulder CHSs, which can result in the development of different end-member geometries. They can also produce localized downturn and rollover geometries driven by diapir collapse by dissolution.

We explain that these variations are controlled by the three-dimensionally variable length and width of the diapir's roof, which is in turn controlled by a volumetrically variable salt flux and sediment accumulation, as opposed to the two-dimensional $A / R$ ratios from previous works. Ultimately, this study improves the understanding of 3D geometries and variability of diapirflank strata and associated salt-sediment interface. This may, in turn, aid in the prediction of sedimentary facies and trap geometries within minibasins and contribute to hydrocarbon exploration in diapiric provinces worldwide.

\section{ACKNOWLEDGMENTS}

600 Special thanks to Oliver Duffy and Mark Rowan for discussions. We also thank Kate Giles, 601 Bruce Trudgill and Juan Martín-Martín for their very constructive reviews and positive criticism, 
602

603

604

605

606

607

608

609

610

611

612

613

614

615

616

617

618

619

620

621

622

623

and Craig Magee for the editorial handling. We thank Condor Petroleum for permission to use and publish the seismic data in this study. We also thank Schlumberger for the academic licenses of seismic interpretation software, Petrel@, and Petroleum Experts for 2D Move@, which was used for depth-conversion and structural restorations.

\section{REFERENCES}

Banham, S. G., \& Mountney, N. P. (2013). Evolution of fluvial systems in salt-walled minibasins: a review and new insights. Sedimentary Geology, 296, 142-166.

Barde, J. P., Chamberlain, P., Galavazi, M., Harwijanto, J., Marsky, J., Gralla, P., \& van den Belt, F. (2002a). Sedimentation during halokinesis: Permo-Triassic reservoirs of the Saigak field, Precaspian basin, Kazakhstan. Petroleum Geoscience, 8(2), 177-187.

Barde, J. P., Gralla, P., Harwijanto, J., \& Marsky, J. (2002b). Exploration at the eastern edge of the Precaspian basin: Impact of data integration on Upper Permian and Triassic prospectivity. AAPG bulletin, 86(3), 399-415.

Brunet, M. F., Volozh, Y. A., Antipov, M. P., \& Lobkovsky, L. I. (1999). The geodynamic evolution of the Precaspian Basin (Kazakhstan) along a north-south section. Tectonophysics, 313(1-2), 85-106.

Duffy, O. B., Fernandez, N., Hudec, M. R., Jackson, M. P., Burg, G., Dooley, T. P., \& Jackson, C. A. L. (2017). Lateral mobility of minibasins during shortening: insights from the SE Precaspian Basin, Kazakhstan. Journal of Structural Geology, 97, 257-276.

Fernandez, N., Duffy, O. B., Hudec, M. R., Jackson, M. P., Burg, G., Jackson, C. A. L., \& Dooley, T. P. (2017). The origin of salt-encased sediment packages: observations from the SE Precaspian Basin (Kazakhstan). Journal of Structural Geology, 97, 237-256. 
624 Fernandez, N., Hudec, M. R., Jackson, C. A. L., Dooley, T. P., \& Duffy, O. B. (2019). The 625 competition for salt and kinematic interactions between minibasins during density-driven 626 subsidence: observations from numerical models. https://doi.org/10.31223/osf.io/jak5u

627 Giles, K. A., Lawton, T. F. (2002). Halokinetic sequence stratigraphy adjacent to the El 628 Papalote diapir, northeastern Mexico. AAPG bulletin, 86(5), 823-840.

629 Giles, K. A., \& Rowan, M. G. (2012). Concepts in halokinetic-sequence deformation and 630 stratigraphy. Geological Society, London, Special Publications, 363(1), 7-31.

631 Giles, K. A., Rowan, M.G., Langford, R., McFarland, J., Hearon, T. (2018) Salt Shoulders in 632 AAPG Search and Discovery, AAPG International Conference and Exhibition, London, 633 England. Hearon, T. E., Rowan, M. G., Giles, K. A., \& Hart, W. H. (2014). Halokinetic deformation 635 adjacent to the deepwater Auger diapir, Garden Banks 470, northern Gulf of Mexico: Testing 636 the applicability of an outcrop-based model using subsurface data. Interpretation, 2(4), SM57637 SM76.

638 Hudec, M. R., \& Jackson, M. P. (2007). Terra infirma: Understanding salt tectonics. Earth639 Science Reviews, 82(1-2), 1-28.

640 Jackson, M. P. A., \& Talbot, C. J. (1991). A glossary of salt tectonics. Bureau of Economic 641 Geology, University of Texas at Austin.

642 Jackson, M. P., \& Hudec, M. R. (2017). Salt tectonics: Principles and practice. Cambridge 643 University Press.

644 Jackson, C. A. L., Duffy, O. B., Fernandez, N., Dooley, T. P., Hudec, M. R., Jackson, M. P., \& 645 Burg, G. (2019). The Stratigraphic Record of Minibasin Subsidence, Precaspian Basin, 646 Kazakhstan. Basin Research. 
647 Kergaravat, C., Ribes, C., Legeay, E., Callot, J. P., Kavak, K. S., \& Ringenbach, J. C. (2016).

648 Minibasins and salt canopy in foreland fold-and-thrust belts: The central Sivas Basin, 649 Turkey. Tectonics, 35(6), 1342-1366.

650 Martín-Martín, J. D., Vergés, J., Saura, E., Moragas, M., Messager, G., Baqués, V., Razin, P., 651 Grélaud, C., Malaval, M., Joussiame, R., Casciello, E., Cruz-Orosa, I., Hunt, D. W. (2017). 652 Diapiric growth within an Early Jurassic rift basin: the Tazoult salt wall (central High Atlas, 653 Morocco). Tectonics, 36(1), 2-32.

654 Matthews, W. J., Hampson, G. J., Trudgill, B. D., \& Underhill, J. R. (2007). Controls on 655 fluviolacustrine reservoir distribution and architecture in passive salt-diapir provinces: Insights 656 from outcrop analogs. AAPG bulletin, 91(10), 1367-1403.

657 Moragas, M., Vergés, J., Saura, E., Martín-Martín, J. D., Messager, G., Merino-Tomé, Ó., ... 658 \& Joussiaume, R. (2018). Jurassic rifting to post-rift subsidence analysis in the Central High 659 Atlas and its relation to salt diapirism. Basin Research, 30, 336-362.

660 Nelson, T. H. (1989). Style of salt diapirs as a function of the stage of evolution and the nature 661 of the encasing sediments. In Gulf Coast Section SEPM Foundation 10th Annual Research 662 Conference Program and Abstracts (pp. 109-110).

663 Rowan, M. G., \& Weimer, P. (1998). Salt-sediment interaction, northern Green Canyon and 664 Ewing bank (offshore Louisiana), northern Gulf of Mexico. AAPG bulletin, 82(5), 1055-1082.

665 Rowan, M. G., Lawton, T. F., Giles, K. A., \& Ratliff, R. A. (2003). Near-salt deformation in La 666 Popa basin, Mexico, and the northern Gulf of Mexico: A general model for passive 667 diapirism. AAPG bulletin, 87(5), 733-756.

668 Rowan, M. G., Giles, K. A., Hearon IV, T. E., \& Fiduk, J. C. (2016). Megaflaps adjacent to salt 669 diapirs. AAPG Bulletin, 100(11), 1723-1747. 
670 Rowan, M. G., \& Ratliff, R. A. (2012). Cross-section restoration of salt-related deformation:

671 Best practices and potential pitfalls. Journal of Structural Geology, 41, 24-37.

672 Saura, E., Vergés, J., Martín-Martín, J. D., Messager, G., Moragas, M., Razin, P., ... \& Hunt, 673 D. W. (2014). Syn-to post-rift diapirism and minibasins of the Central High Atlas (Morocco):

674 the changing face of a mountain belt. Journal of the Geological Society, 171(1), 97-105.

675 Sclater, J. G., \& Christie, P. A. (1980). Continental stretching: An explanation of the post-Mid-

676 Cretaceous subsidence of the central North Sea Basin. Journal of Geophysical Research:

677 Solid Earth, 85(B7), 3711-3739.

678 Volozh, Y. A., Antipov, M. P., Brunet, M. F., Garagash, I. A., Lobkovskii, L. I., \& Cadet, J. P. 679 (2003). Pre-Mesozoic geodynamics of the Precaspian basin (Kazakhstan). Sedimentary 680 Geology, 156(1-4), 35-58.

681 Vendeville, B. C., \& Jackson, M. P. (1992). The rise of diapirs during thin-skinned 682 extension. Marine and Petroleum Geology, 9(4), 331-354. 
(a)

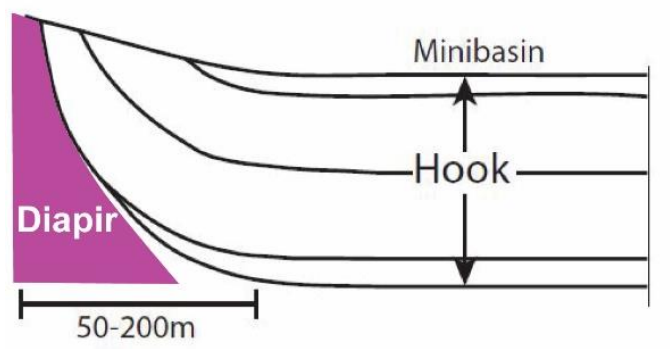

Halokinetic Sequences (HS)

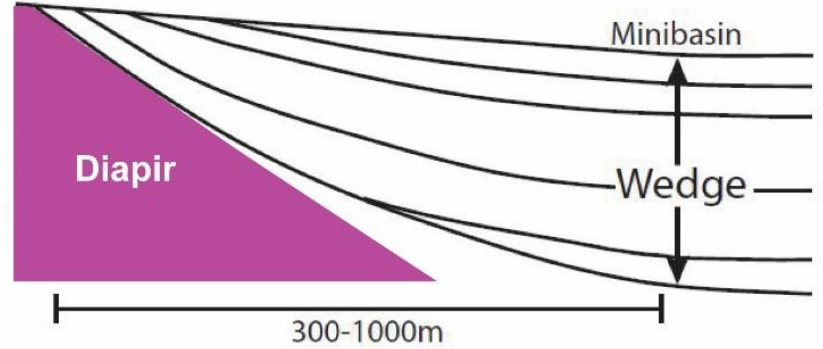

(b)

Composite Halokinetic Sequences (CHS)
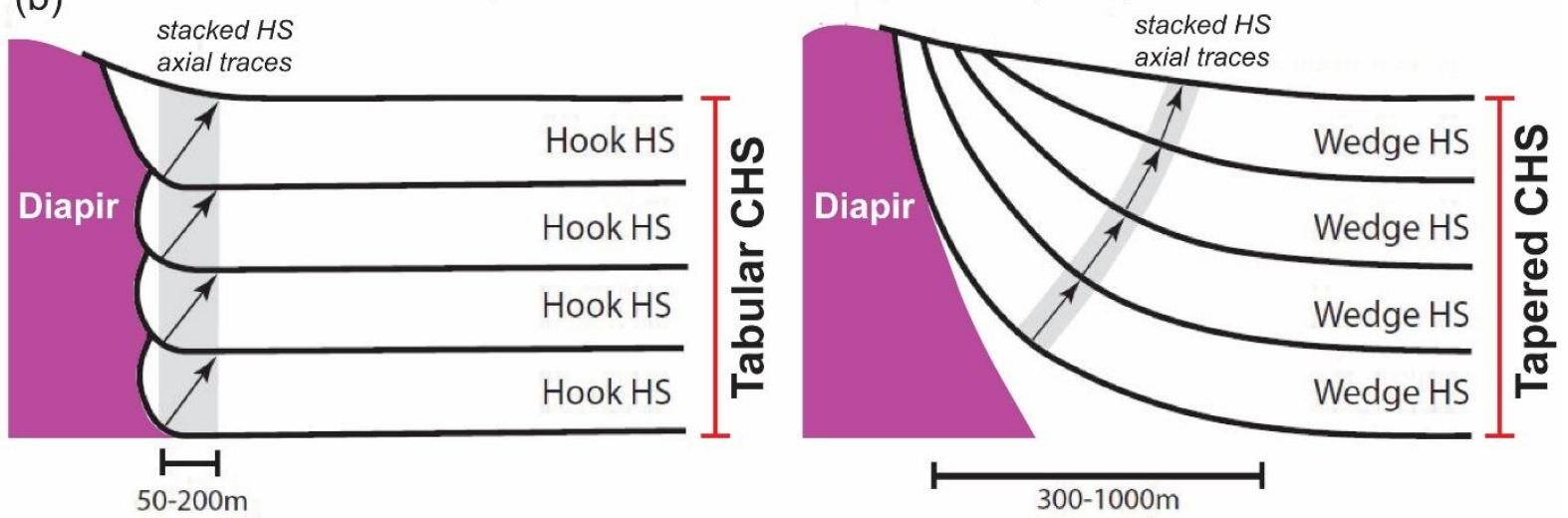

Figure 1: (a) End-members of halokinetic sequences (HS), hooks and wedges. (b) End-members of composite halokinetic sequences (CHS), tabular and tapered. Adapted from Giles and Rowan (2012). 


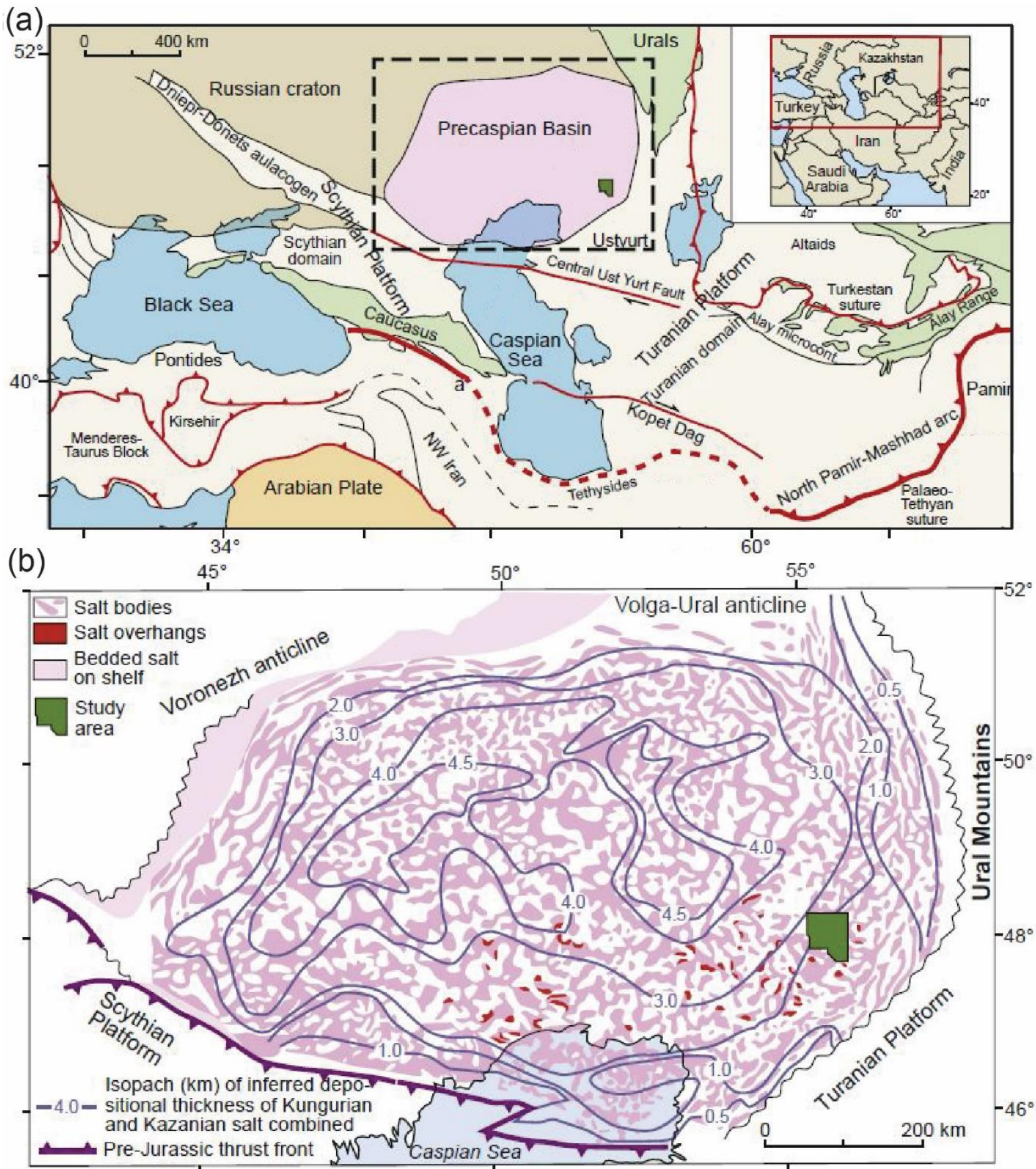

(c) $\mathrm{NW}$

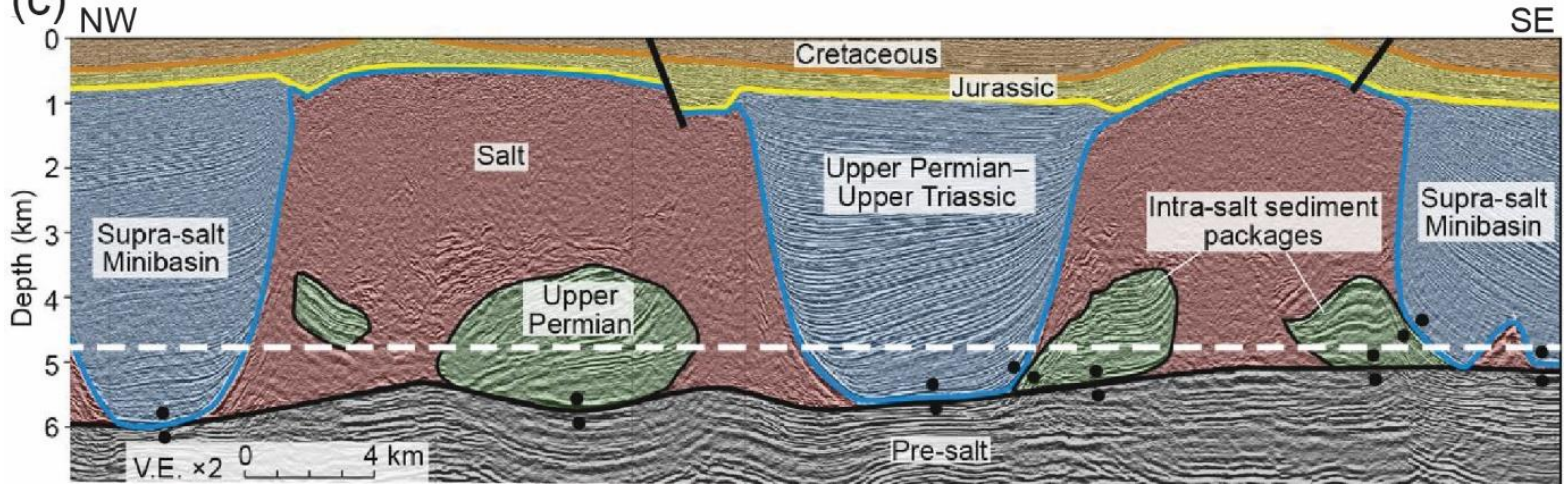

Figure 2 - (a) Regional geological map showing the location and geodynamic context of the Precaspian 
al., 2017 and after Natal'in and Sengor, 2005). (b) Composite salt thickness and structure map adapted from Volozh et al (2003a) and Duffy et al (2017) showing the location of the 3D survey utilized in this study. (c) Composite seismic section illustrating the main salt tectonic structural elements in the studyarea, e.g. large salt walls, encased minibasins and Upper Permian-Upper Triassic supra-salt minibasins, the focus of this study (adapted from Duffy et al., 2017). The minibasins are capped by a major base Jurassic erosional unconformity (BJU) that is represented by a yellow line in the section.

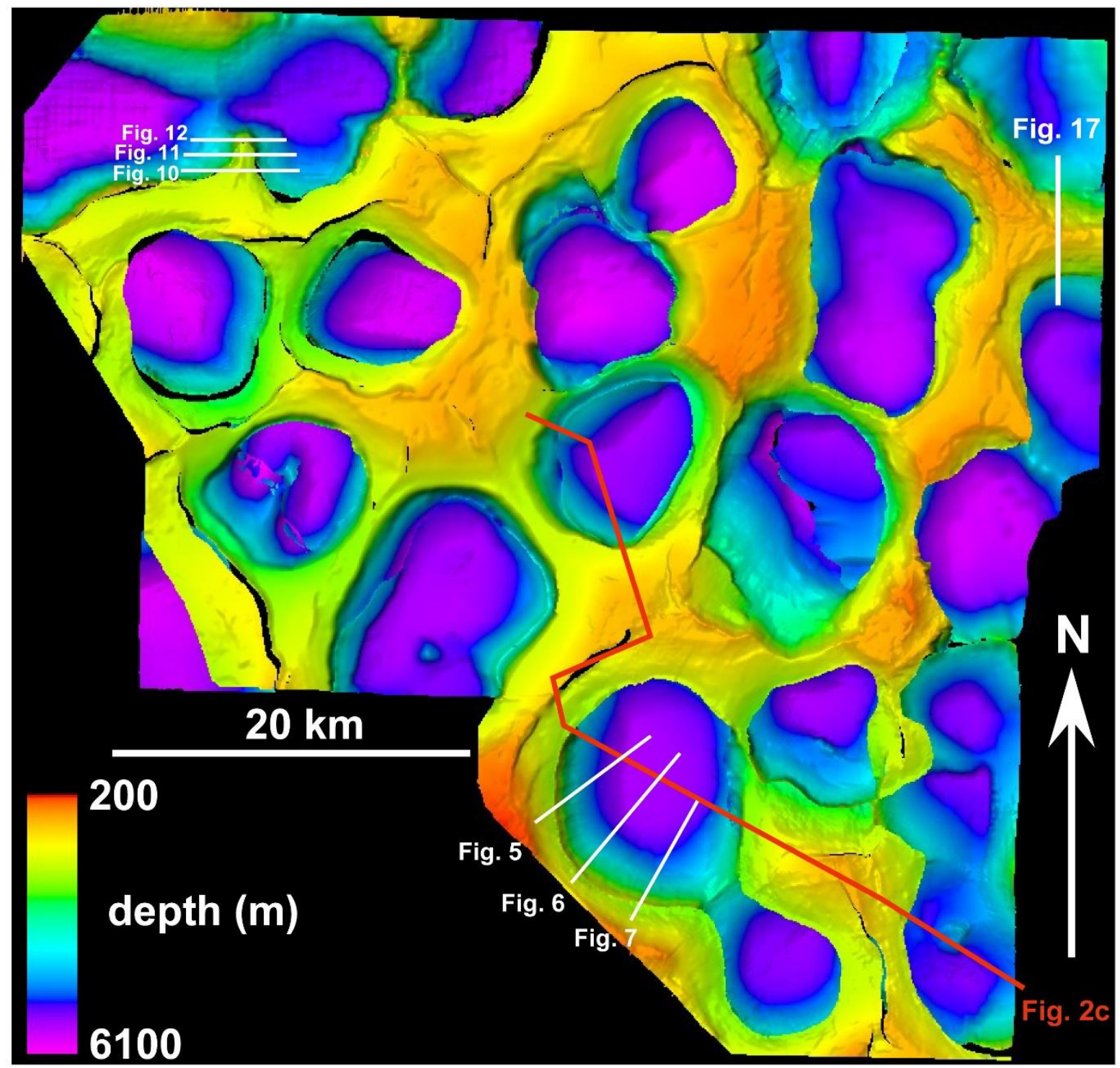

697

Figure 3: Top Salt Depth-Map illustrating the polygonal structural framework of salt walls and elliptical to sub-circular minibasins in the study-area. The seismic sections presented in this study are indicated in white and another composite section from Duffy et al. (2017) in red. 
(a) Inclined Diapir Flank

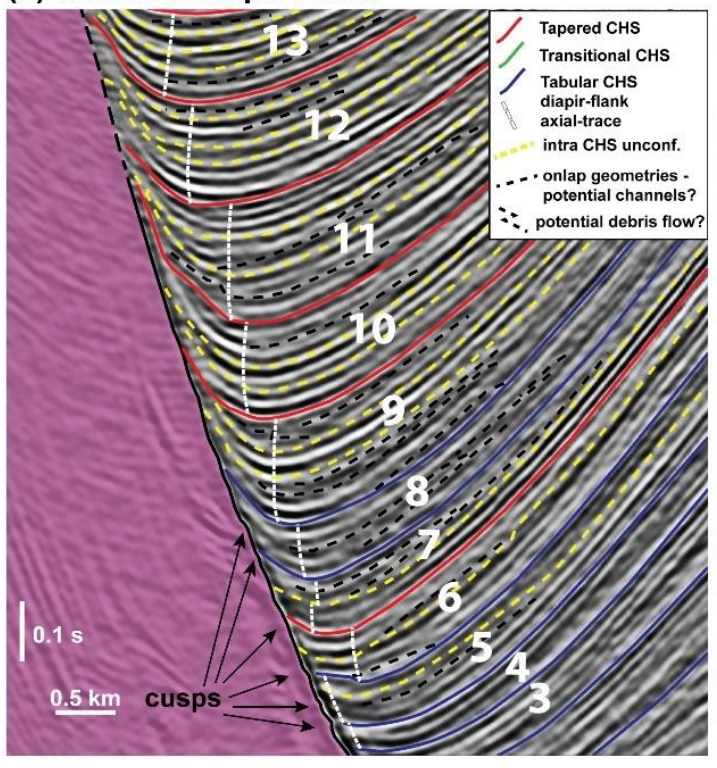

(b) Vertical Diapir

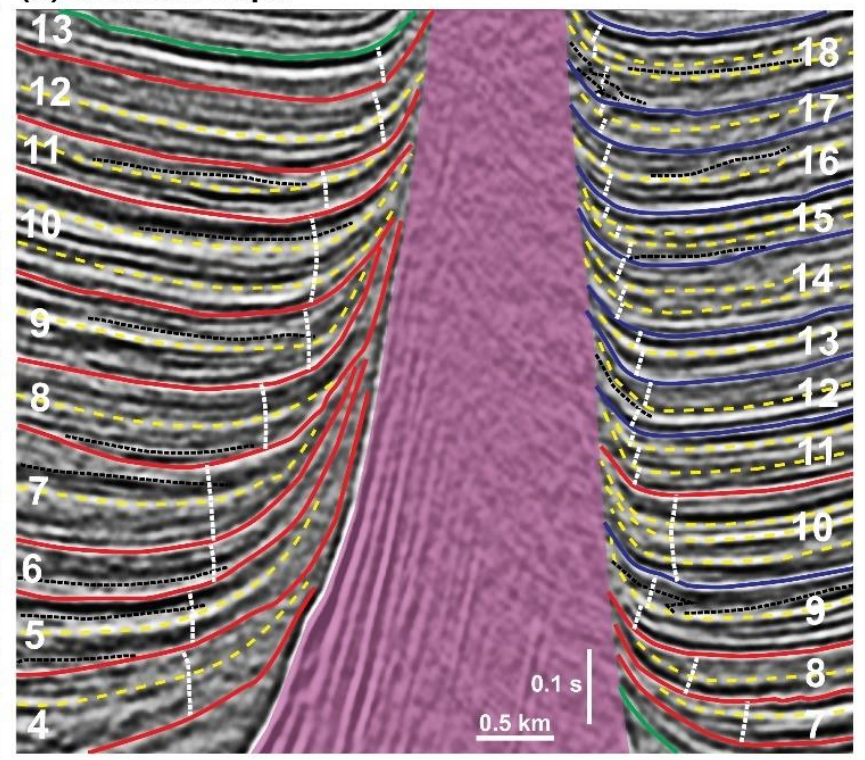

Figure 4: Uninterpreted and Interpreted representative sections showing CHS variability and detailed stratal architecture across two distinct diapir-flank geometries: (a) inclined diapir flank and (b) vertical diapir. Intra-CHS unconformities (yellow dashed lines) relate to $4^{\text {th }}$ order Halokinetic Sequences. Basal onlaps and stratigraphic terminations are indicated in black dashed lines and may potentially indicate channels and debris-flow deposits at/near the depositional axis of CHSs. 


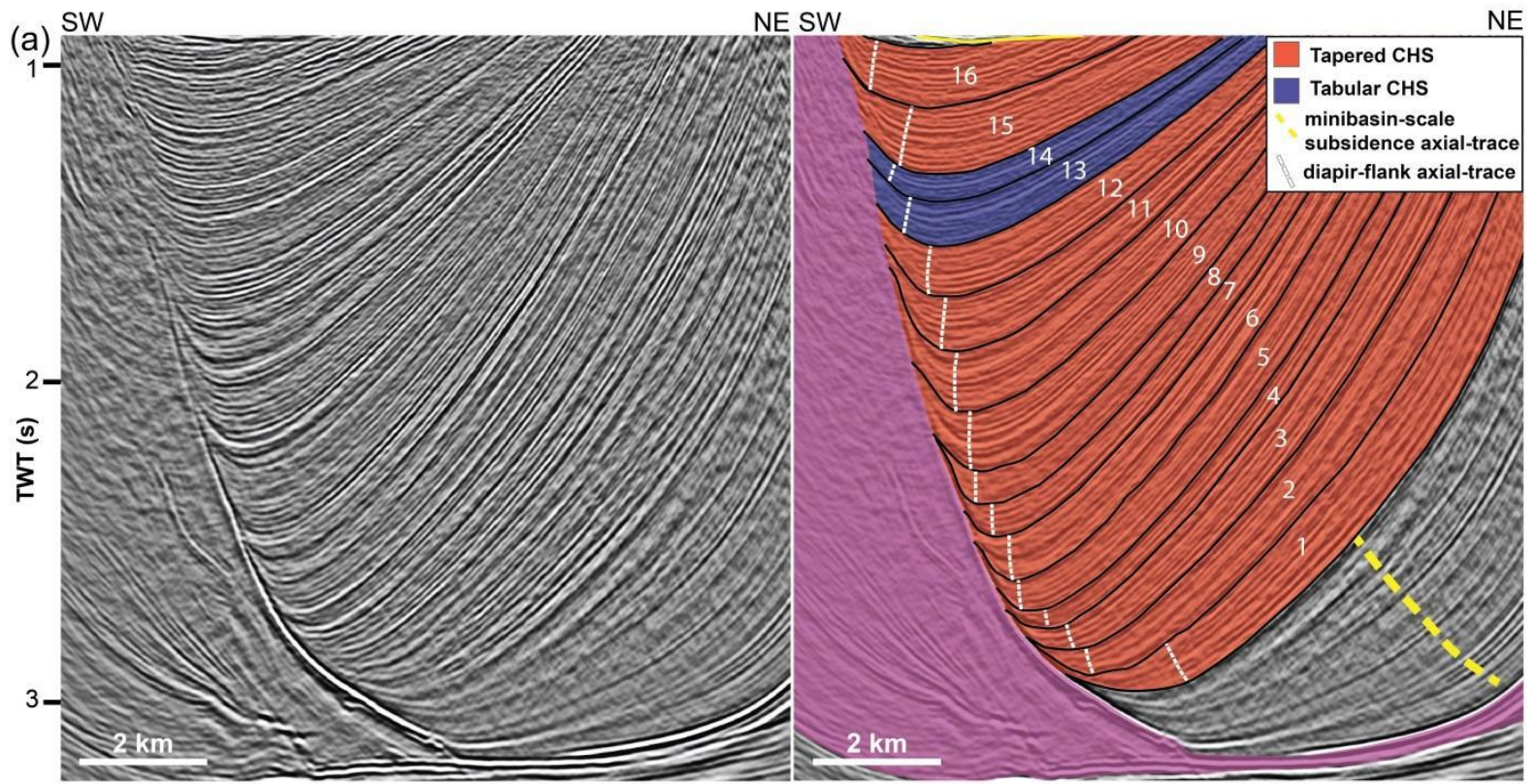

(b) SW

Depth-converted Section

$\mathrm{NE}$

707

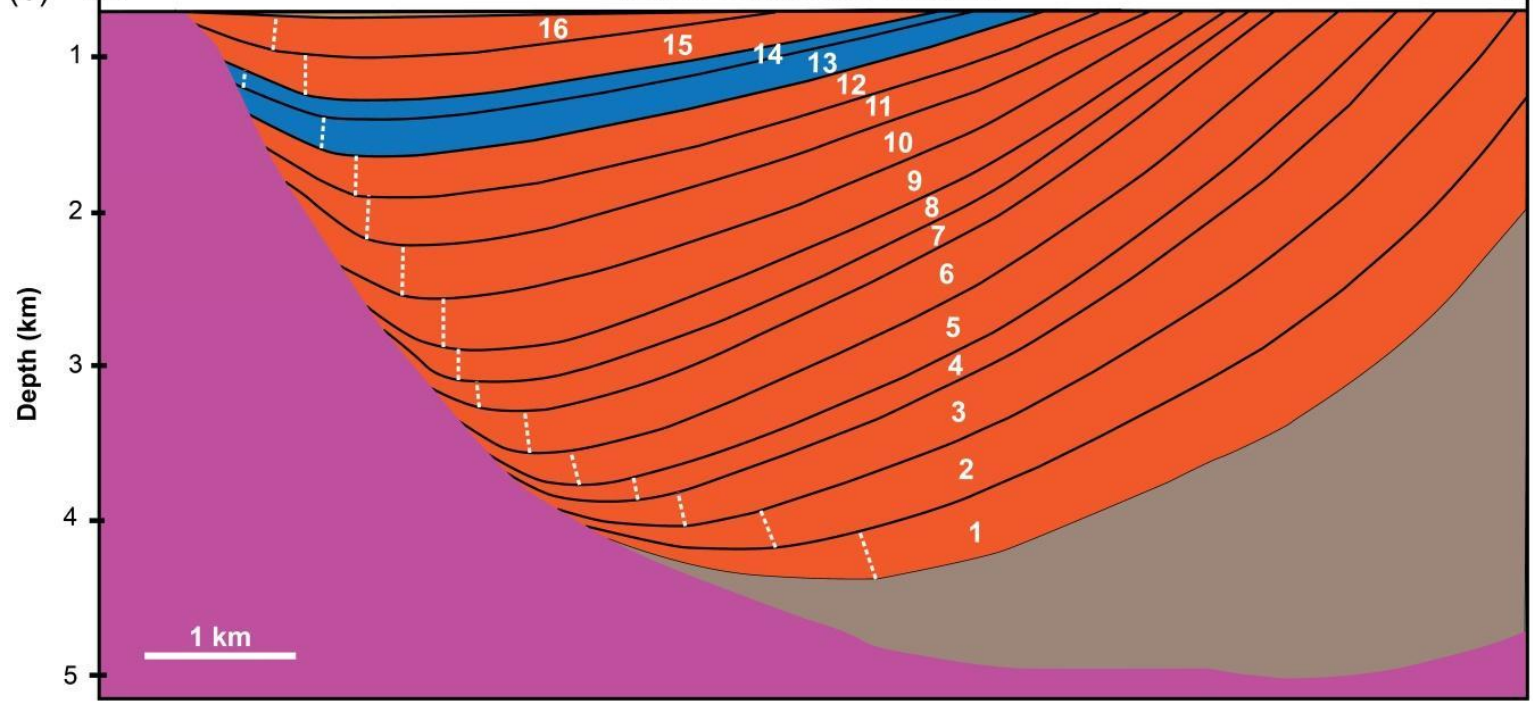

708

Figure 5: (a) Uninterpreted and interpreted seismic profiles of Section 1 illustrating minibasin and CHS

architecture in the northern portion of the inclined salt wall. (c) Depth-converted section. Minibasin strata

are tilted to the southwest due to shortening and uplift of a salt wall to the northeast of the section. The

lowermost minibasin section (brown) is characterized by a broad, bowl-shape geometry indicating 
(a) SW

NE SW
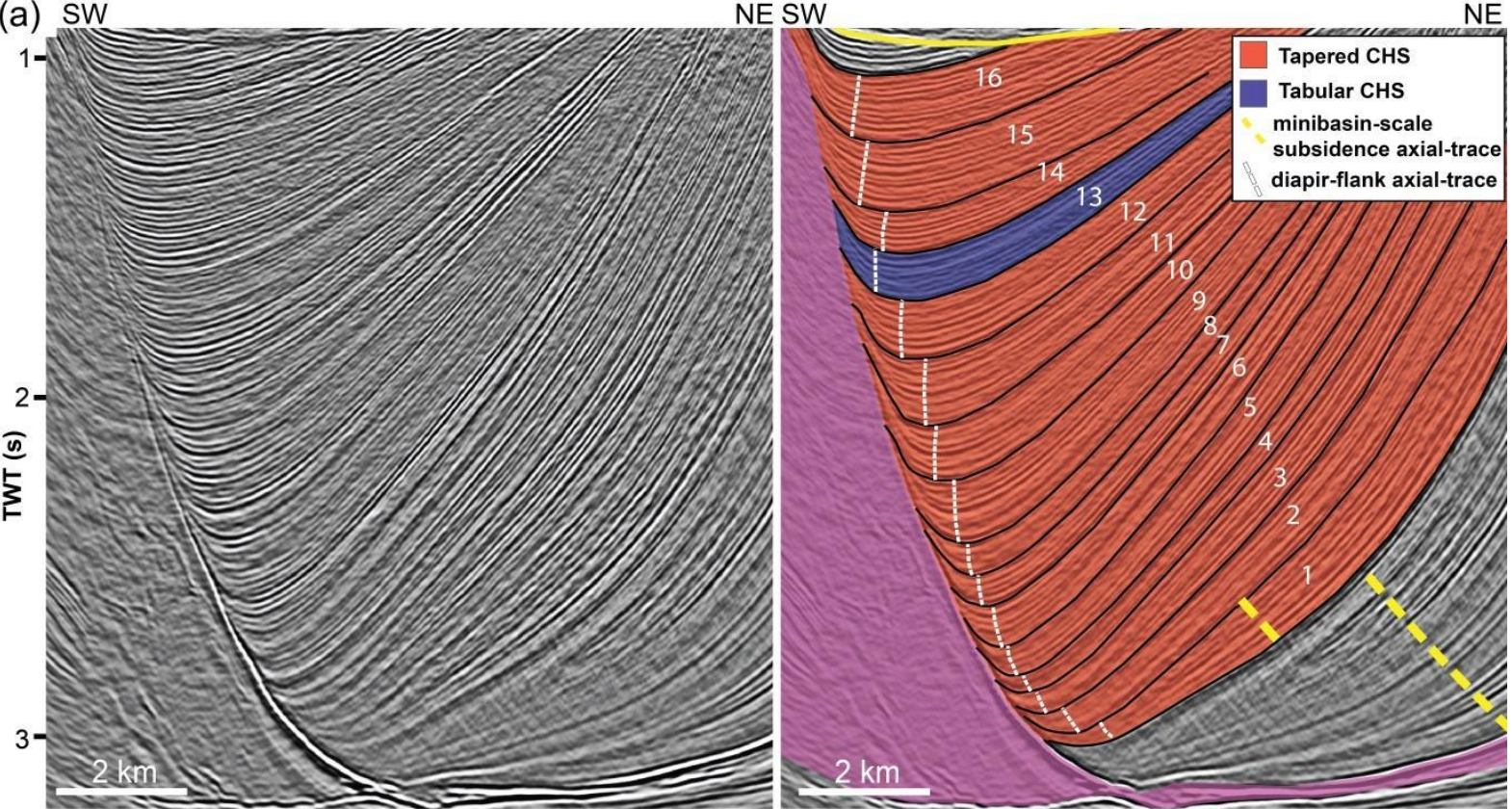

(b)

Depth-converted Section

$\mathrm{NE}$

714

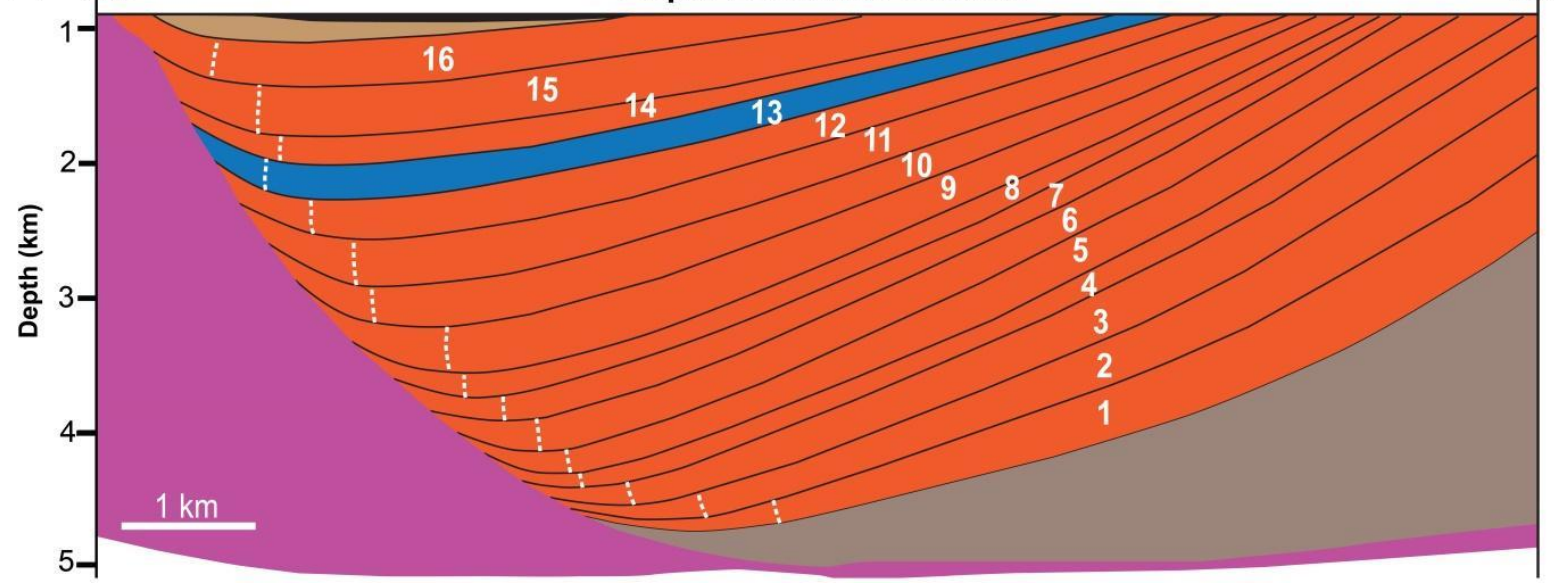

Figure 6: (a) Uninterpreted and interpreted seismic profiles of Section 2 illustrating minibasin and CHS architecture in the central portion of the inclined salt wall. (c) Depth-converted section. Minibasin strata are tilted to the southwest due to shortening and uplift of a salt wall to the northeast of the section. The lowermost minibasin section (brown) is characterized by a broad, bowl-shape geometry indicating minibasin-scale subsidence. This section is overlain by a large-scale wedge succession composed of a series of CHSs dominated by tapered geometries with only one tabular $\mathrm{CHS}$. 


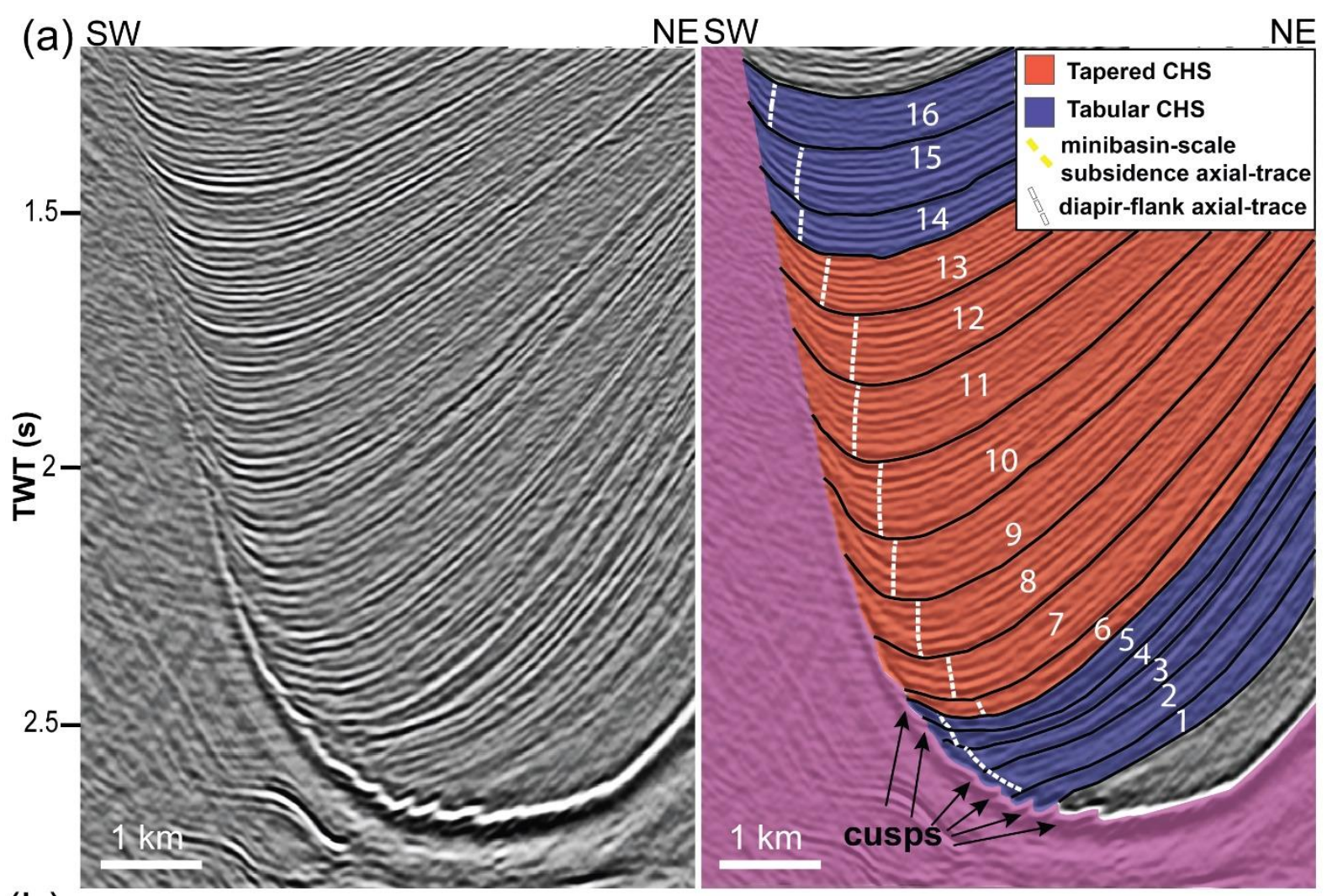

(b) sw

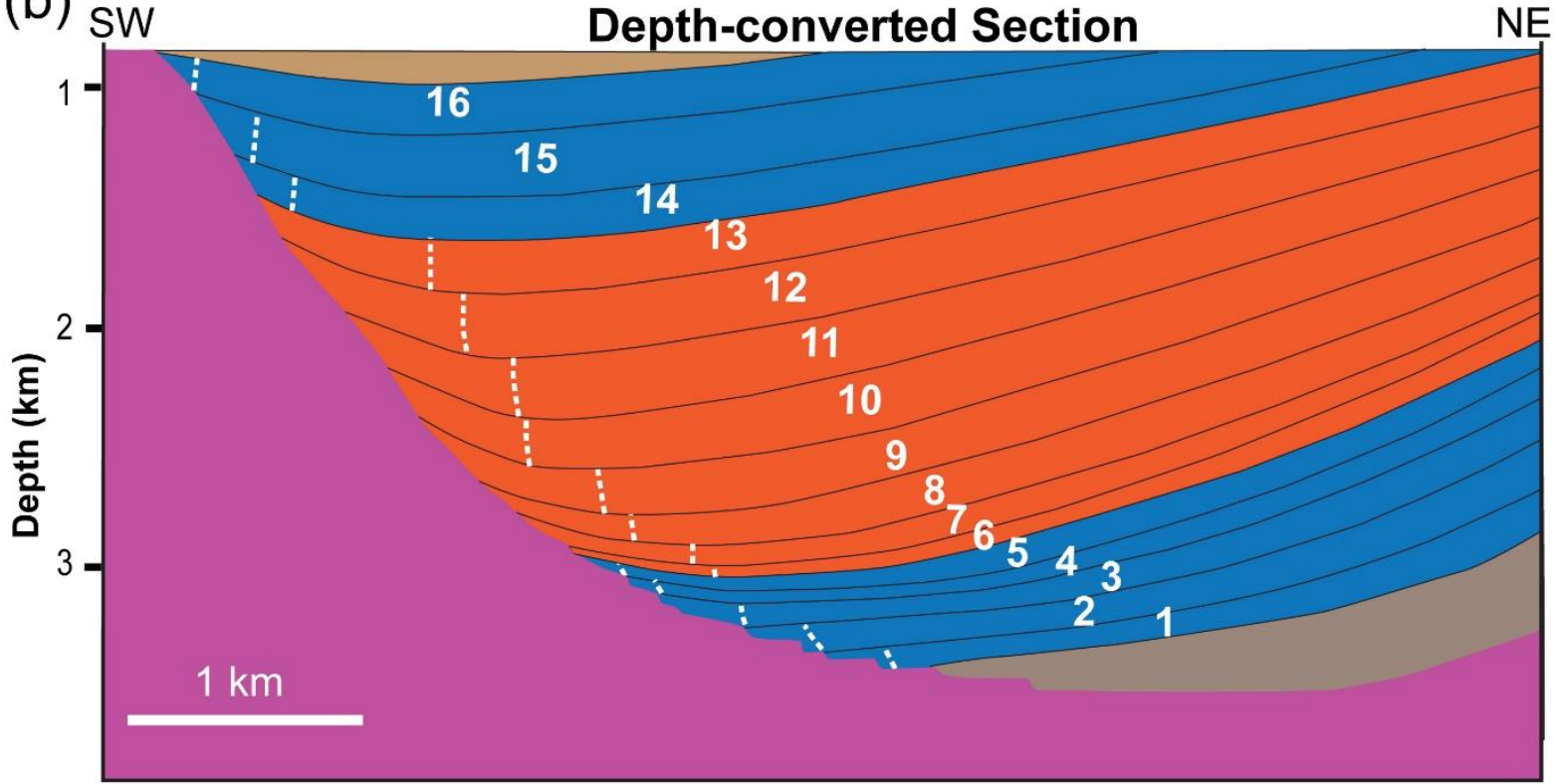

722 Figure 7: (a) Uninterpreted and interpreted seismic profiles of Section 3 illustrating minibasin and CHS architecture in the northern portion of the inclined salt wall. (c) Depth-converted section. Minibasin strata are tilted to the southwest due to shortening and uplift of a salt wall to the northeast of the section. Lower and uppermost undifferentiated sequences in brown and CHSs in blue and red according to their end-member geometries. The succession shows an equal proportion of tabular (blue) and tapered (red) end-members and an atypical vertical zonation characterized by lower and upper tabular CHSs and 


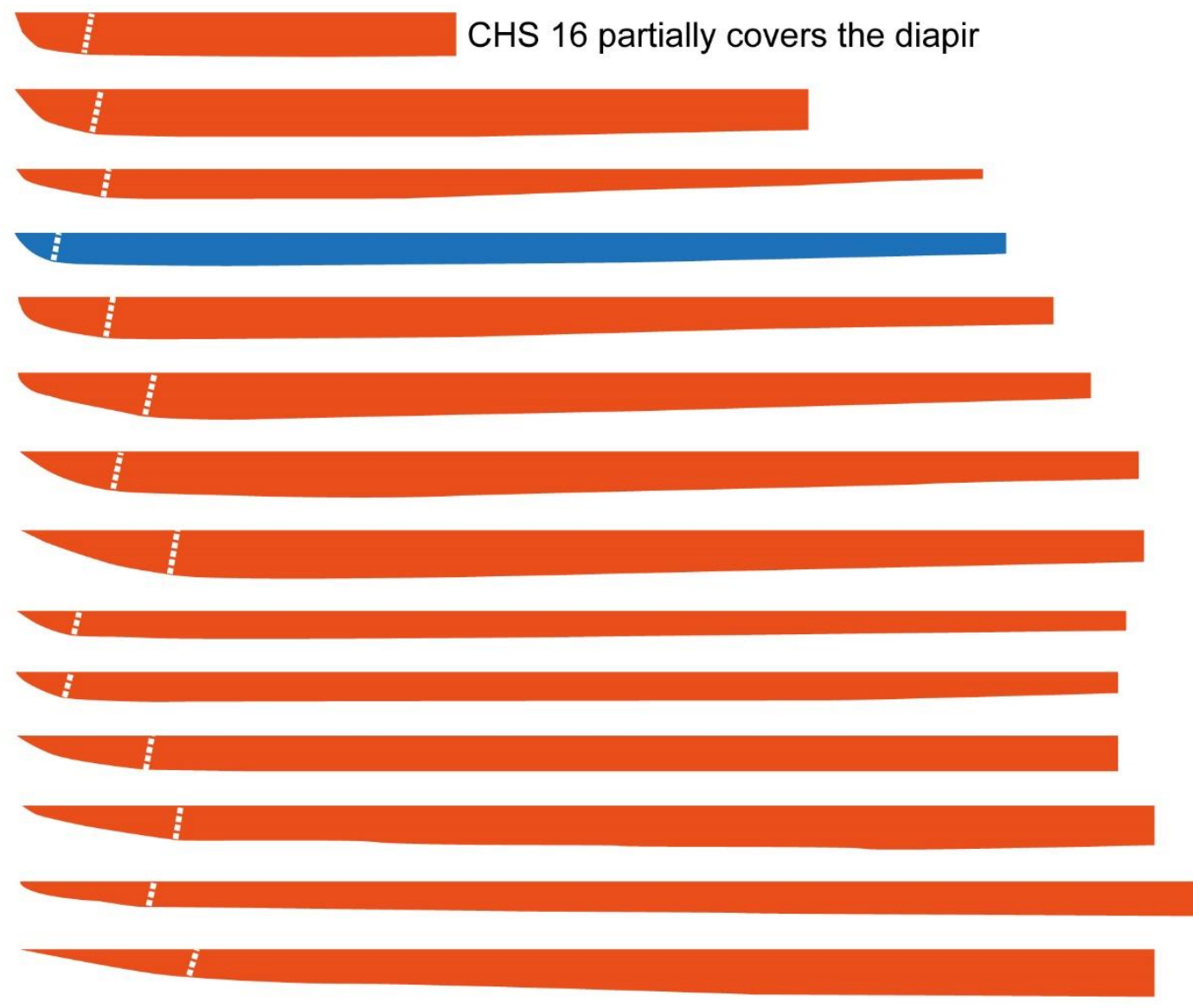

CHS 16

CHS 15

CHS 14

CHS 13

CHS 12

CHS 11

CHS 10

CHS 9

CHS 8

CHS 7

CHS 6

CHS 5

CHS 4

CHS 3

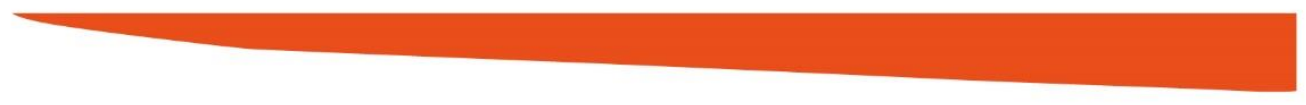

CHS 2

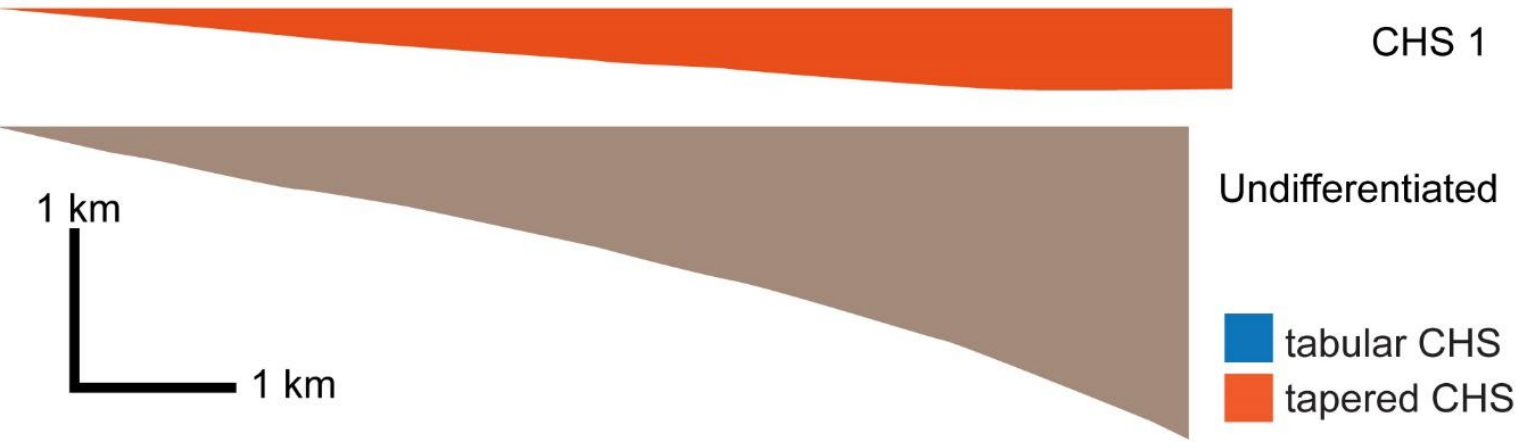

Figure 8: Central section (Section 2) analysis demonstrating the restored geometry and classification for each CHS identified. Dashed white lines represent the restored depositional axial traces associated with monoclinal drape folding characteristic of the CHS development. In many CHSs, especially oldest CHSs, the influence of broader-scale minibasin subsidence produce very subtle, low-amplitude and high wavelength stratal thinning, which hinders the definition of CHSs 1-2 axial trace. 
CHS 15

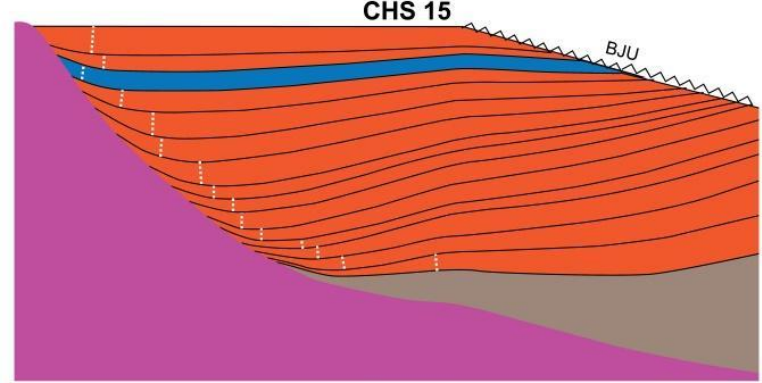

CHS 13

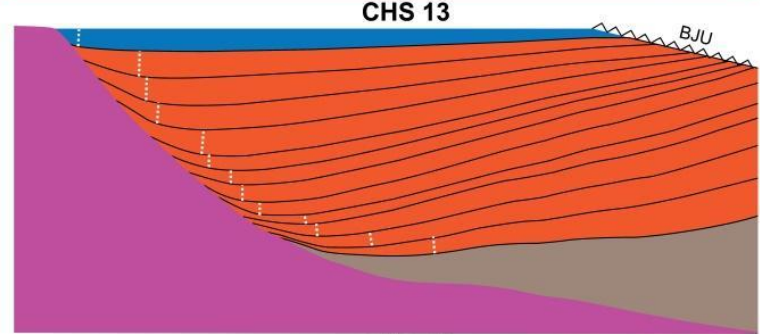

CHS 11

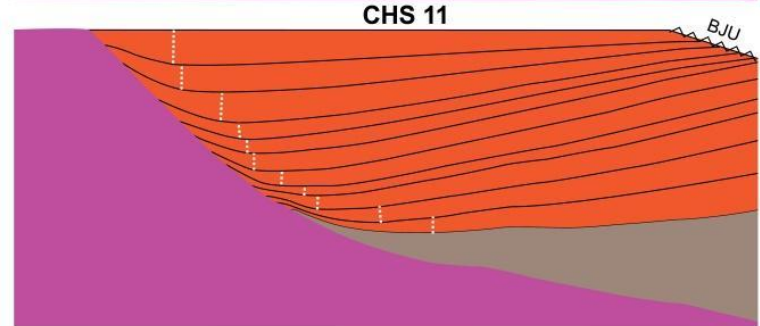

CHS 8

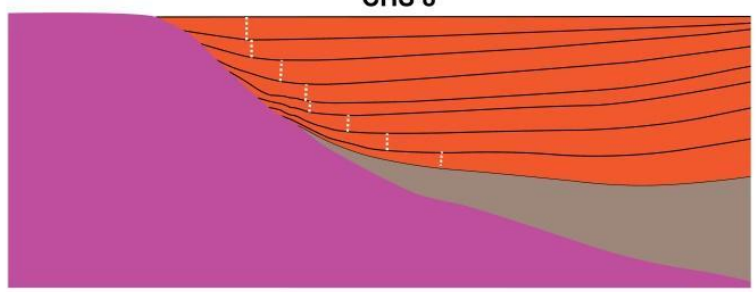

CHS 5

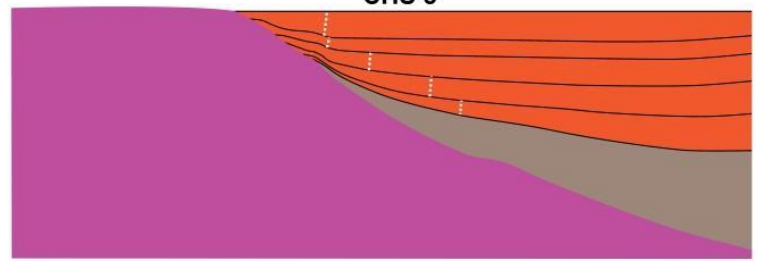

CHS 3

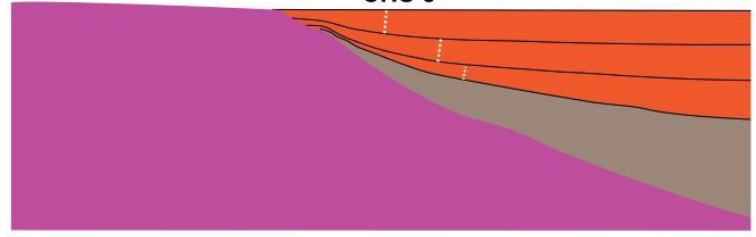

tabular $\mathrm{CHS}$ transitional $\mathrm{CHS}$

tapered $\mathrm{CHS} \quad$ indifferentiated

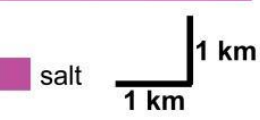

Figure 9: Sequential restoration of the central section (Section 2) showing the main, most representative steps of minibasin subsidence, development of CHS and their relationship with changes in diapir-flank geometries associated with the inclined salt wall. BJU is the Base-Jurassic Unconformity. The whitedashed lines represent restored CHS axial-traces. 

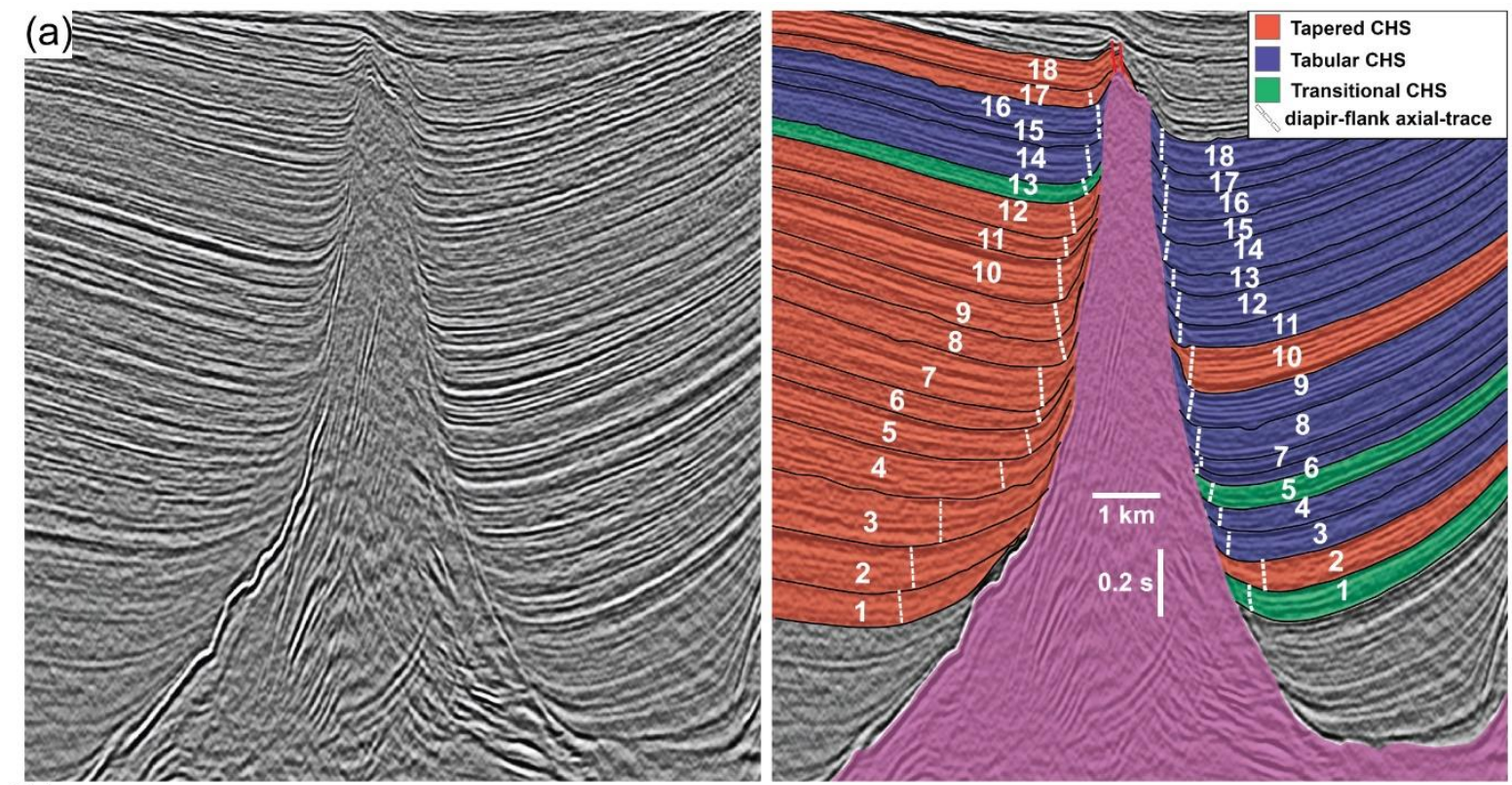

(b)

Depth-converted Section

$\mathrm{E}$

741

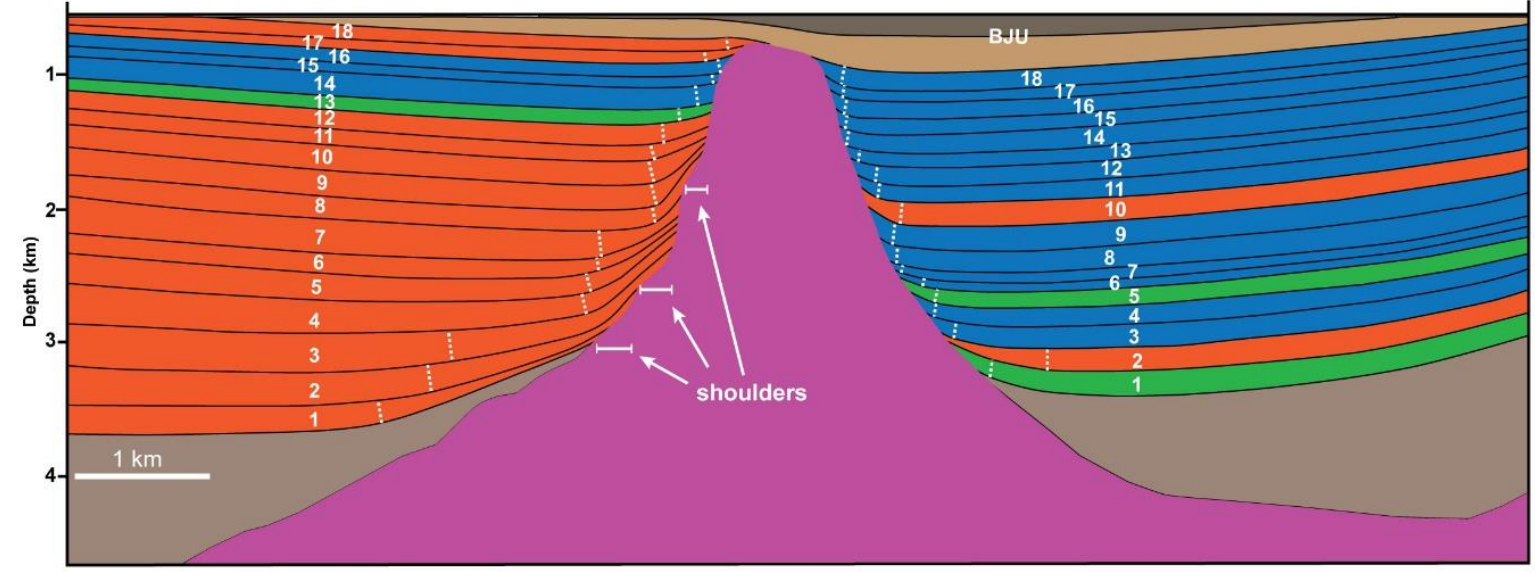

742 Figure 10: (a) Uninterpreted and interpreted seismic profiles of Section 1 illustrating minibasin and CHS

architecture and variability along the southern portion of the vertical salt wall. (b) Depth-converted section. These sections show how the large majority of CHSs change laterally to different CHS endmembers along-strike and around the vertical diapir. The western minibasin is dominated by tapered end-members whereas the eastern by tabular end-members. The lowermost minibasin section (brown) is characterized by a broad, bowl-shape geometry indicating minibasin-scale, broadly symmetric subsidence. Uppermost section (light brown) is undifferentiated as it partially covers the diapir and do not present CHSs. BJU is Base-Jurassic Unconformity. 

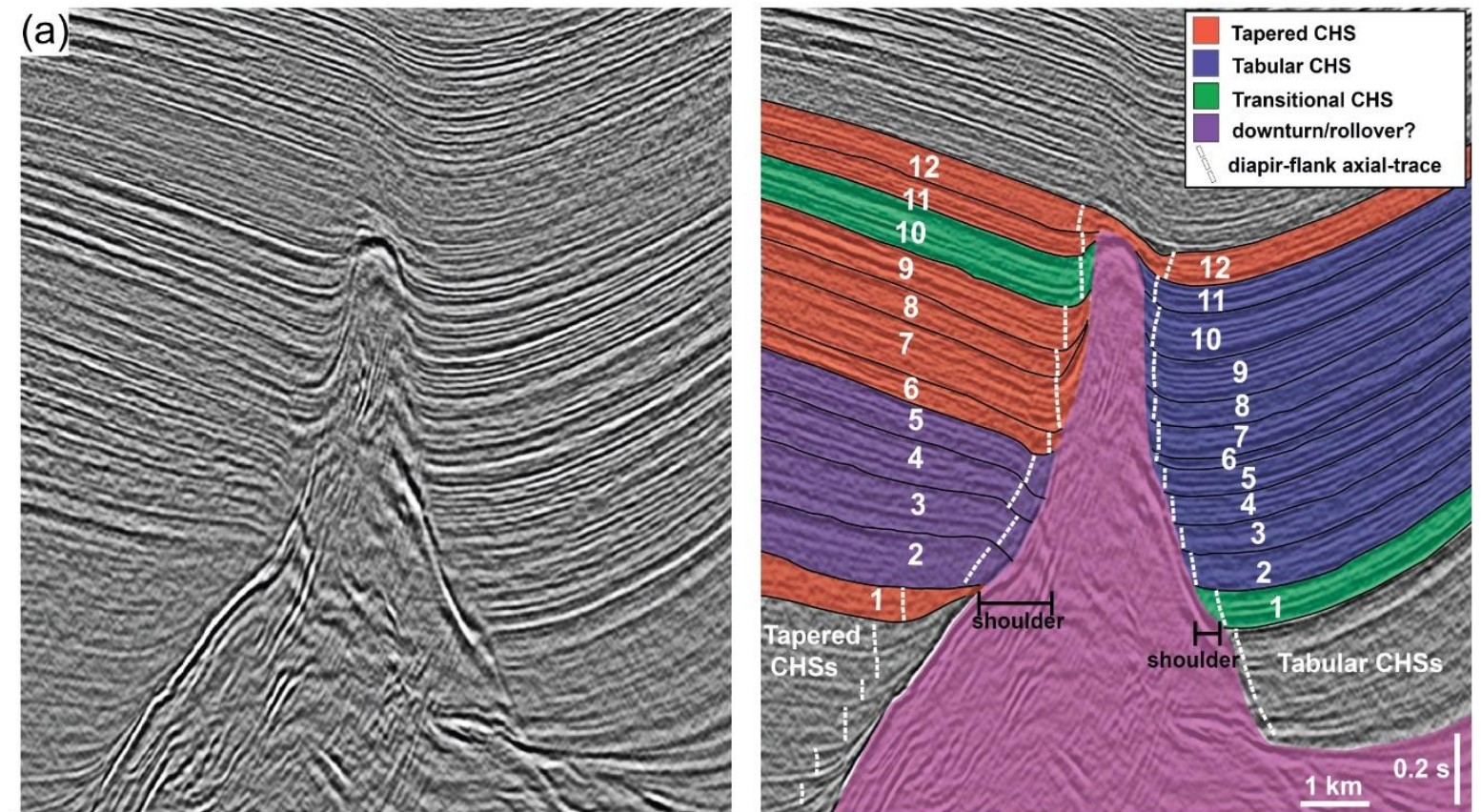

(b)w

Depth-converted Section

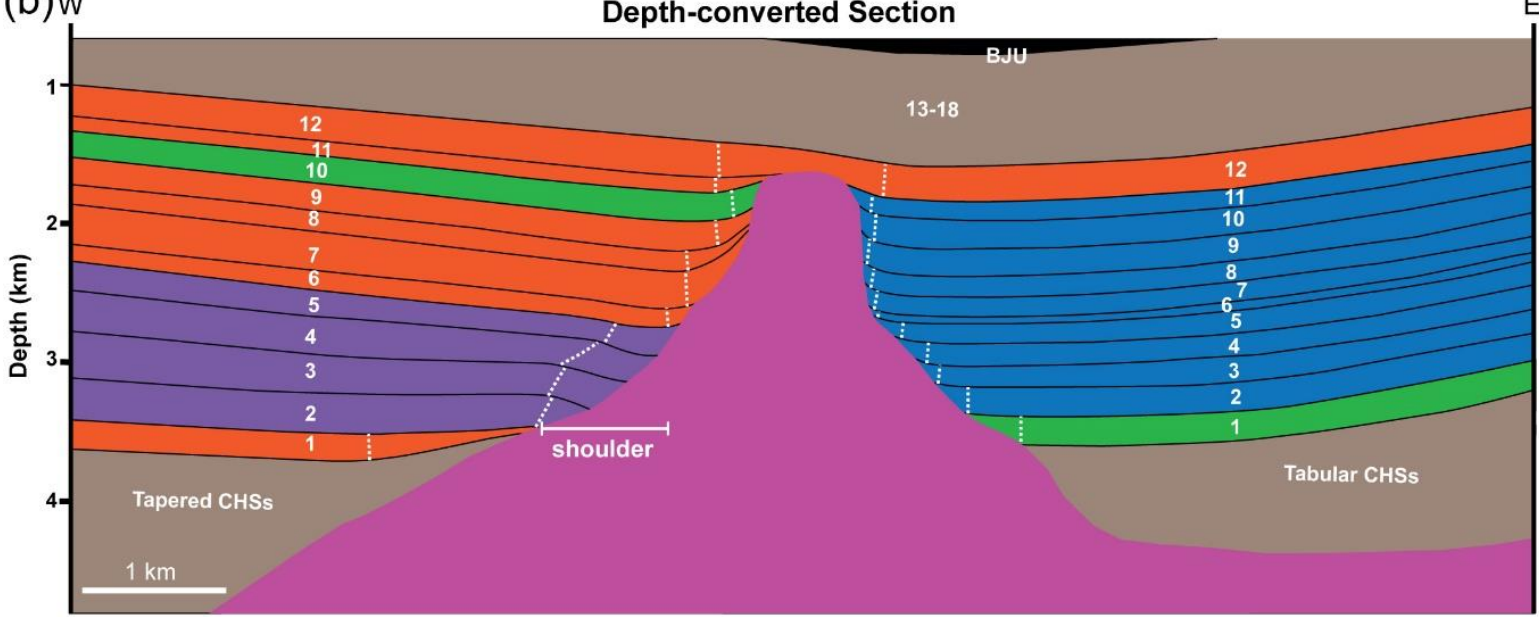

Figure 11: (a) Uninterpreted and interpreted seismic profiles of Section 2 illustrating minibasin and CHS architecture and variability along the central portion of the vertical salt wall. (b) Depth-converted section. Illustrating drastic variability of CHS style across the vertical salt wall, with the eastern minibasin dominated by tabular CHSs and the western minibasin by tapered CHSs. The eastern minibasin presents intermediate sequences with rollover geometries characterized by downturning and thickening towards the diapir above a salt shoulder. The lowermost minibasin section is not numbered but is characterized by tabular CHSs geometries to the east and tapered geometries to the west. The upper section (light brown) is equivalent to the CHSs 13-18 from further south (section 1) but, here, as they cover the diapir, they are not classified as CHSs and, thus, are undifferentiated. BJU is Base-Jurassic Unconformity. 

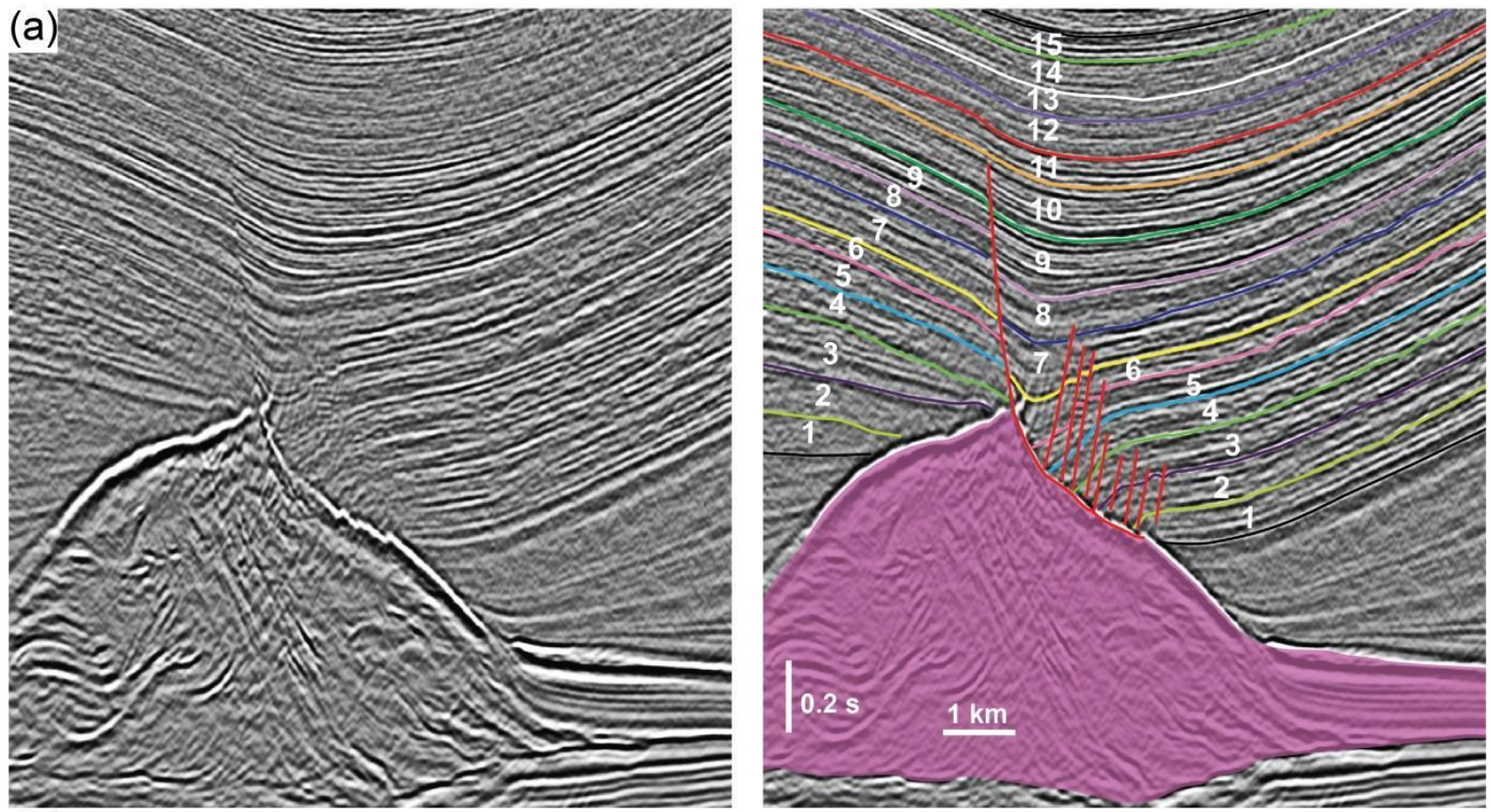

(b) w

E

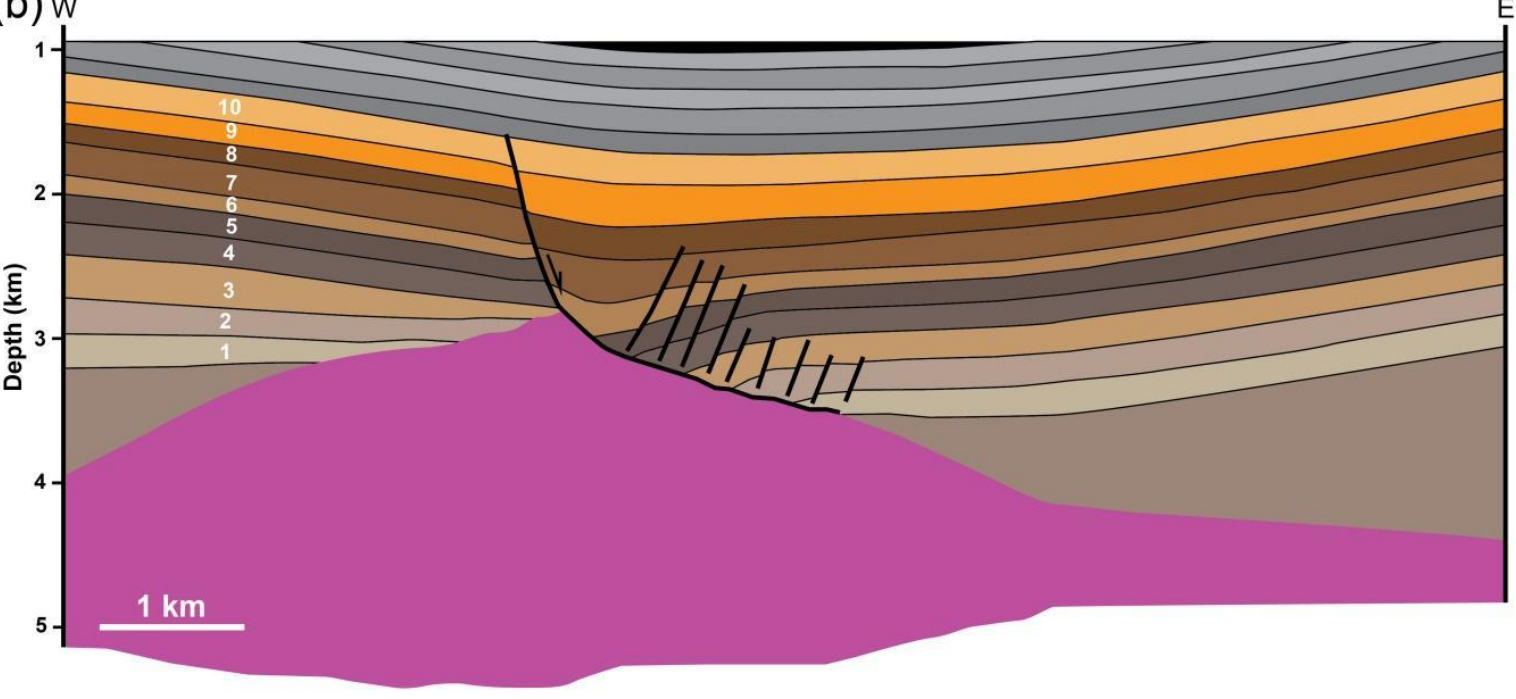

761

762 Figure 12: (a) Uninterpreted and interpreted seismic profiles of Section 3, and (b) depth-converted

763 section showing how the salt wall changes to the north to a low-relief salt roller defined by a listric

764 normal fault and a west-dipping extensional rollover. Sequences 1-10 (warm colours) demonstrate

rollover and/or hanging-wall thickening geometries denoting syn-extension deposition. Strata equivalent

to CHSs further south are no longer classified as CHSs as they are controlled and deformed by the listric normal fault, not being associated with passive diapirism. 


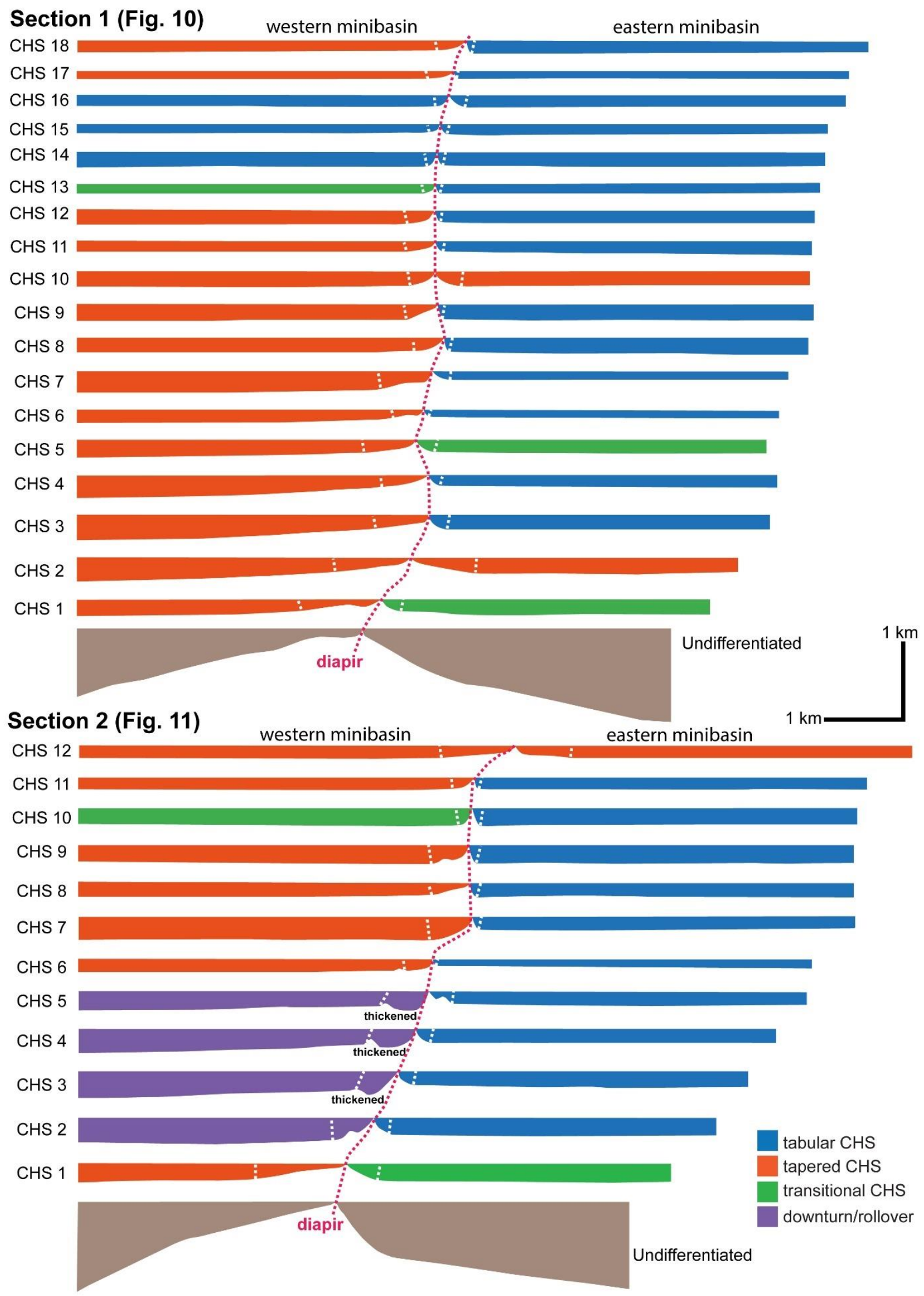

Figure 13: Section analysis for (a) Section 1 (south) and (b) Section 2 (central) demonstrating the 771 restored geometry and classification for each $\mathrm{CHS}$ on both western and eastern minibasins around the 


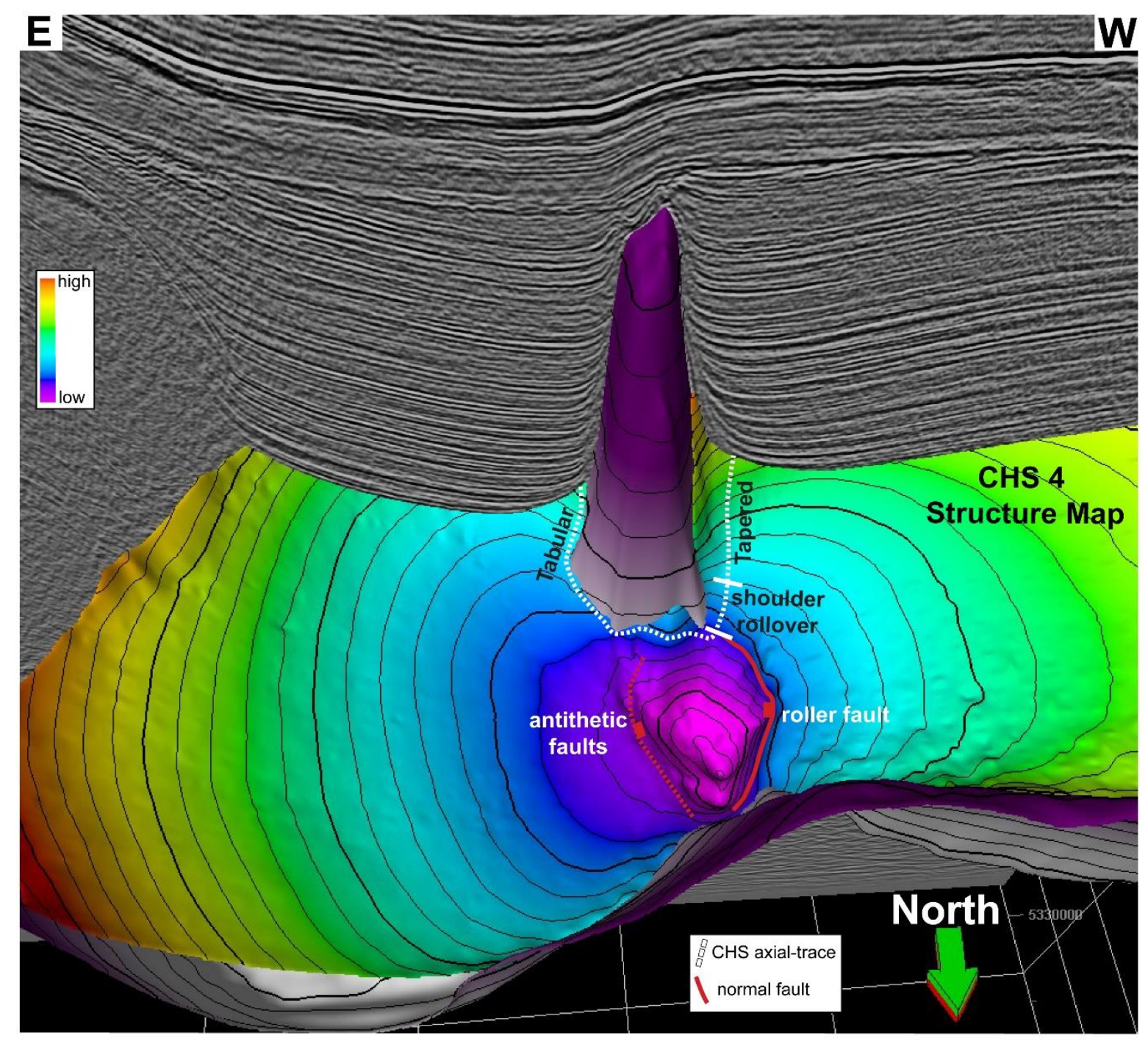

Figure 14: $3 D$ view of the vertical salt wall combined to the CHS 4 structure map demonstrating how

CHS architecture changes along-strike and around the wall from tabular CHS geometries to the east and north of the wall to an intermediate rollover above a salt shoulder to the northwest and to tapered associated with a salt roller. 


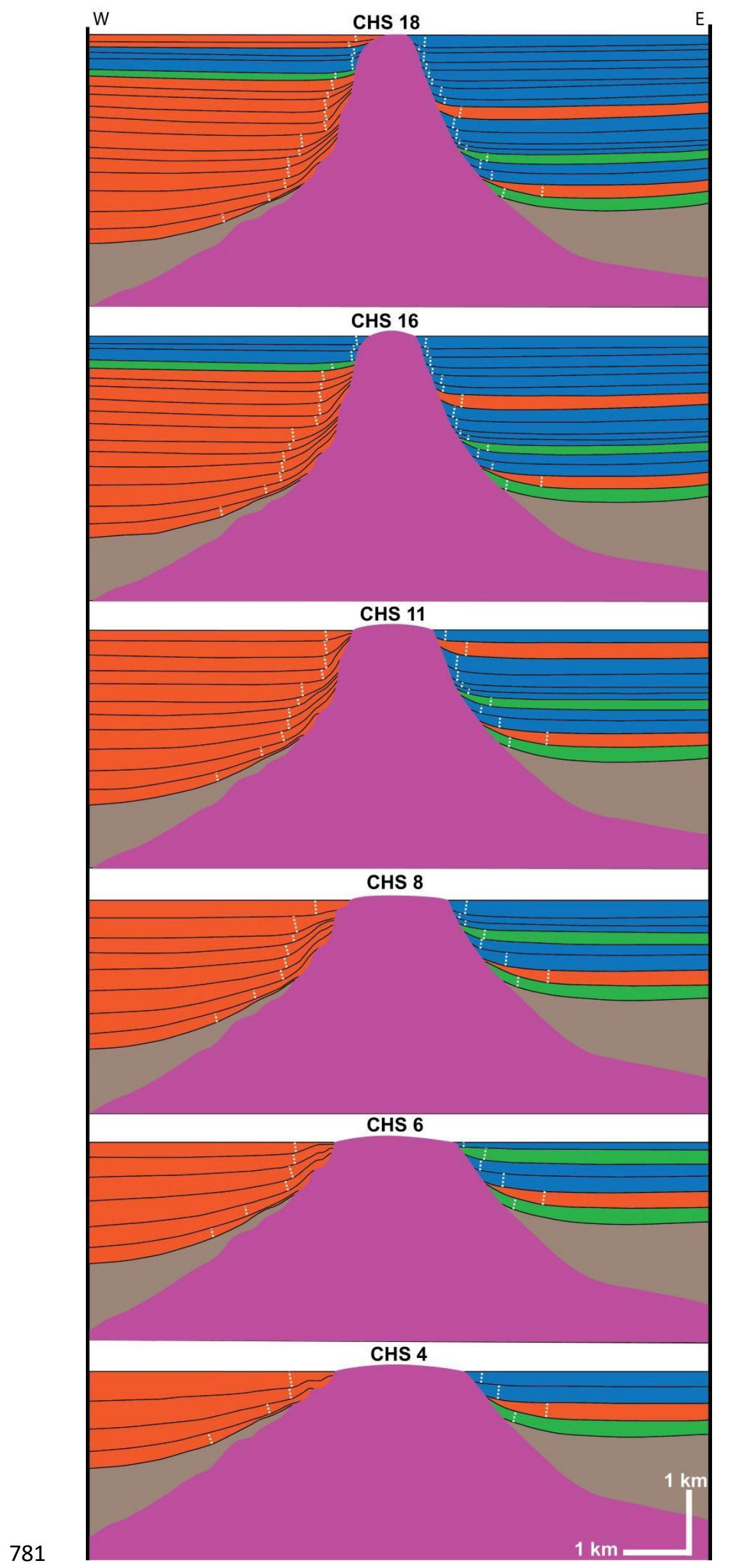


Figure 15: Sequential restoration of the southern section (Section 1, figure 10) of the vertical salt wall showing the most representative steps of development of CHS and their relationship with changes in diapir geometries. BJU is Base-Jurassic Unconformity. The white-dashed lines represent restored CHS axial-traces. For the colour classification scheme and figure caption, see figure 9 and 16 .
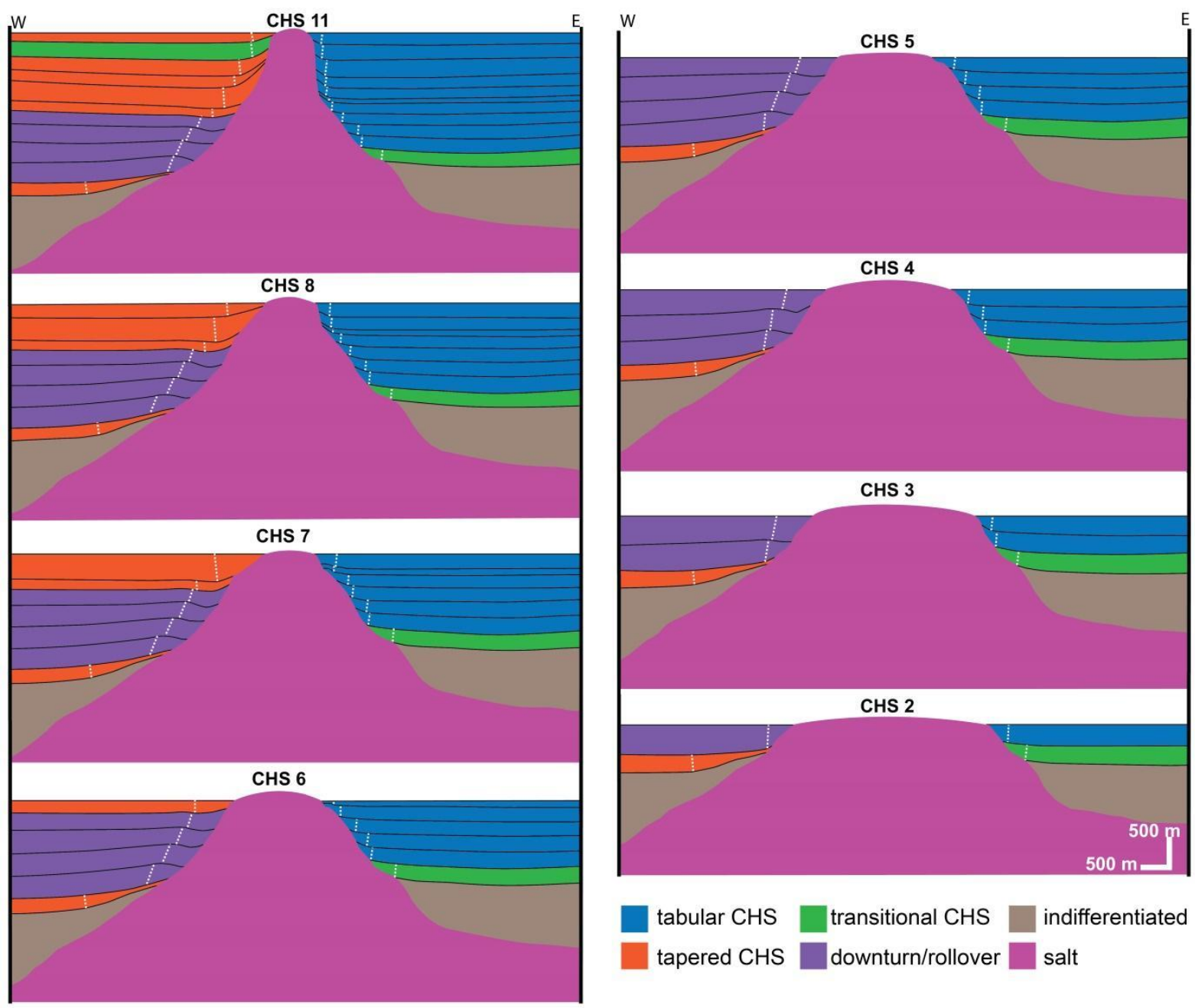

Figure 16: Sequential restoration of the central section (Section 2, figure 11) of the vertical salt wall showing the most representative steps of development of CHS and their relationship with diapir geometries. BJU is Base-Jurassic Unconformity. The white-dashed lines represent restored CHS axialtraces. 


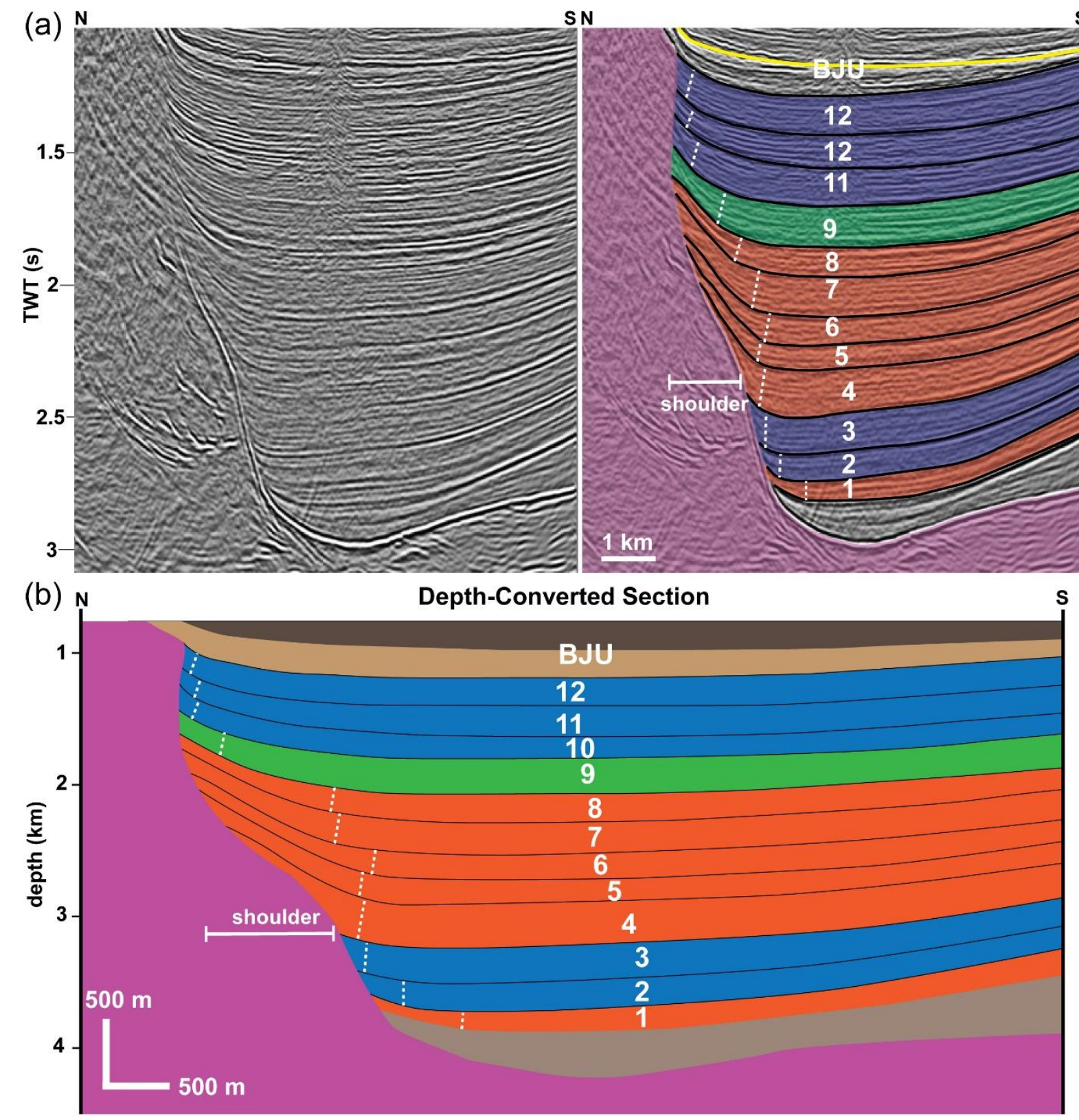

792 Figure 17: (a) uninterpreted and interpreted seismic sections illustrating a CHS succession from a

793 different minibasin in the north of the study-area and the transition from pre-shoulder tabular CHSs to

794 tapered geometries with significantly wider $(c .500 \mathrm{~m})$ zone of folding and stratal thinning over the

795 shoulder. White dashed lines indicate CHS axial-trace. (c) Depth-converted section. Yellow line

796 indicates the BJU, Base-Jurassic Unconformity. For colour scheme and classification, see figures 10

797 and 16. 


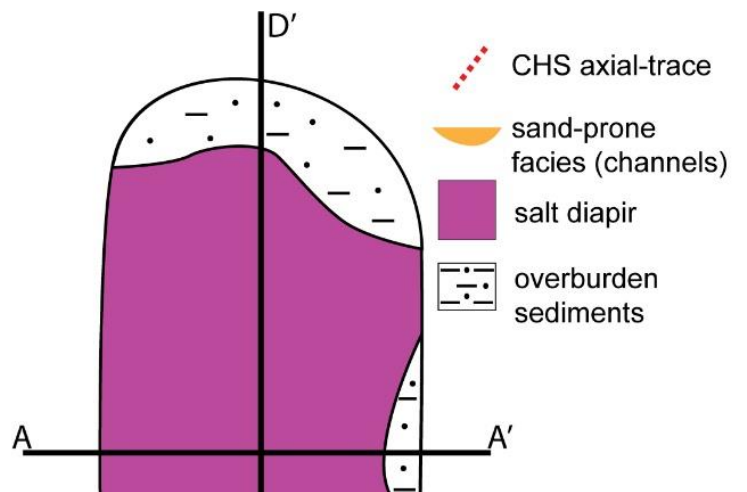

TABULAR-TAPERED

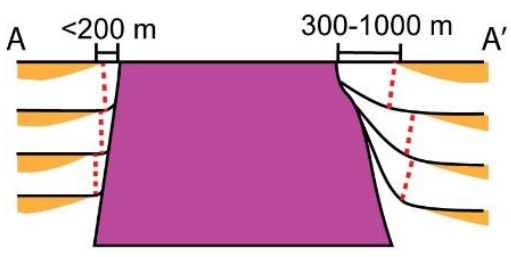

TABULAR-TABULAR

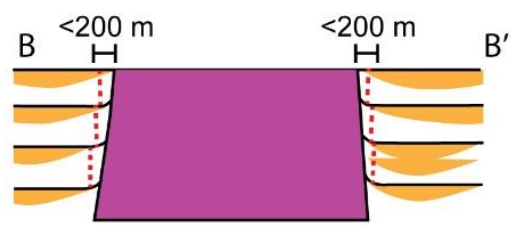

TAPERED-TAPERED

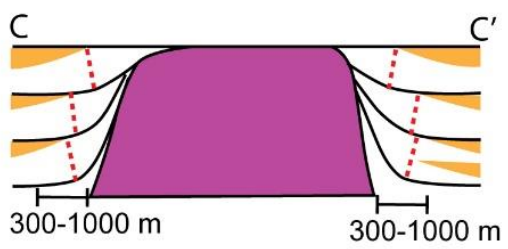

TABULAR-TAPERED

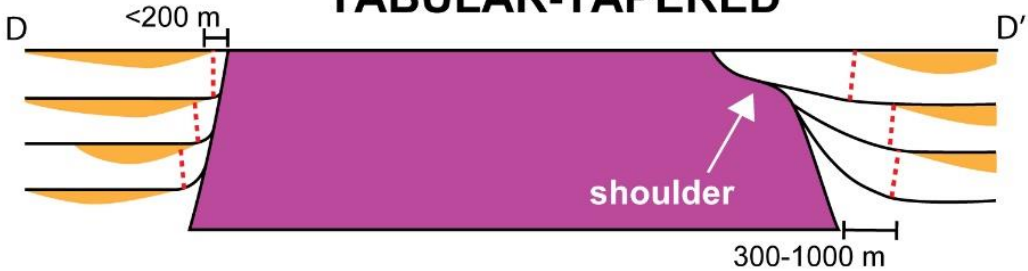

799 Figure 18: Diagram summarizing how diapir-flank and CHS geometries can vary three-dimensionally and how this is influenced by how further inboard the cover the diapir, which is turn a consequence of volumetrically variable salt flux and sediment accumulation rate. They present variable geometries and, in cases, contrasting end-members along a single diapir. This may result in laterally variable distribution of sand-prone facies in clastic-dominated systems and, ultimately on diapir-flank reservoir pinch-out. Tabular geometries will have updip pinch-outs located up to $200 \mathrm{~m}$ from the salt-sediment interface whereas in tapered geometries this distance will range from 300-1000 m. 


\begin{tabular}{|c|c|c|c|c|c|c|c|c|c|c|c|c|c|}
\hline \multicolumn{14}{|c|}{ Inclined Wall } \\
\hline \multirow{2}{*}{\multicolumn{4}{|c|}{$\begin{array}{l}\frac{5 \text { Section } n \text { (Northerm) }}{\text { Depth-Converted }} \\
\end{array}$}} & \multicolumn{6}{|c|}{ Section 2 (Central) } & \multicolumn{4}{|c|}{ Section 3 (Southern) } \\
\hline & & & & & & Depth-Converted & & Restored & & & & Depth-Converted & \\
\hline & Taper Angle & Width of Thinning/Folding zone $(\mathrm{m})$ & CHS type & & $\begin{array}{l}\text { Taper Angle } \\
\end{array}$ & Witth of Thinning/Folding zone & Taper Angle & Width of Thinning/Folding zone $(\mathrm{m})$ & CHS type & & $\begin{array}{l}\text { Taper Angle } \\
\end{array}$ & Width of Thinning/Folding zone $(\mathrm{m})$ & CHS type \\
\hline CHS16 & & & Tapered & CHS16 & & & 22 & 540 & Tapered & CHS16 & & & Tapered \\
\hline CHS15 & 30 & 690 & Tapered & CHS15 & 45 & 390 & 32 & 450 & Tapered & CHS15 & 40 & 390 & Tapered \\
\hline CHS14 & 64 & 90 & Tabular & CHS14 & 33 & 550 & 19 & 630 & Tapered & CHS14 & 60 & 100 & Tabular \\
\hline CHS13 & 62 & 130 & Tabular & CHS13 & 60 & 170 & 54 & 190 & Tabular & CHS13 & 34 & 470 & Tapered \\
\hline CHS12 & 32 & 750 & Tapered & CHS12 & 38 & 580 & 23 & 770 & Tapered & CHS12 & 44 & 360 & Tapered \\
\hline CHS11 & 34 & 750 & Tapered & CHS11 & 33 & 800 & 21 & 950 & Tapered & CHS11 & 33 & 590 & Tapered \\
\hline CHS10 & 37 & 860 & Tapered & CHS10 & 37 & 6900 & 26 & 640 & Tapered & CHS10 & 34 & 560 & Tapered \\
\hline $\begin{array}{l}\text { CHSS } \\
\text { CHS8 }\end{array}$ & 年 30 & 680 & $\begin{array}{l}\text { Tapered } \\
\text { Taped }\end{array}$ & $\begin{array}{l}\text { CHS9 } \\
\text { CHSB }\end{array}$ & 年2 & 60 & ${ }_{17}^{22}$ & 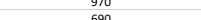 & Tapered & CHSS & 22 & 800 & Tapered \\
\hline CHS 7 & 31 & 790 & & CHS 7 & 16 & 850 & & 950 & & CHS 7 & 10 & 930 & tapered \\
\hline CHS6 & 28 & 730 & Tapered & CHS6 & 22 & 745 & 20 & 840 & Tapered & CHSG & 8 & 860 & Taper \\
\hline CHSS & & 900 & Tapered & CHSS & 18 & 860 & 16 & 980 & Tapered & CHSS & 8 & 900 & Tapered \\
\hline & 16 & 940 & & CHS4 & 20 & 640 & 11 & 850 & Tapered & 54 & & 140 & Tabular \\
\hline CHS3 & 13 & 1250 & Tapered & CHS3 & 11 & 900 & 14 & 975 & Tapered & CHS3 & & 130 & Tabular \\
\hline 52 & 11 & 1350 & Tapered & CHS2 & 5 & 1320 & 12 & 1450 & B-scale & CHS2 & & 185 & Tabular \\
\hline CHS1 & 10 & 2100 & \begin{tabular}{|l|l} 
MB-scale \\
\end{tabular} & CHS1 & & & 7 & $\sim 4500$ & MB-scale & CHS1 & & 175 & Tabular \\
\hline
\end{tabular}

813 Table 1: Classification and metrics of each CHS mapped in the sections (1-3) for the inclined salt wall.

814 Measurements were obtained from depth-converted sections. For the central section we compare these 815 values for both present-day and restored geometries. The widths of folding were measured from the inflection points to the tips of each CHS and taper angles by straight lines connecting these two points.

\begin{tabular}{|c|c|c|c|c|c|c|c|c|c|c|}
\hline \multicolumn{11}{|c|}{ Vertical Wall Section 1} \\
\hline & Restored & & Depth-Converted & & SSIFICATI & & & Depth-Converted & & Restored \\
\hline Taper Angle & Width of Thinning/Folding zone & Taper Angle & Width of Thinning/Folding zone & LEFT MB & & RIGHT MB & Taper Angle & Width of Thinning/Folding zone & Taper Angle & Width of Thinning/Folding zone \\
\hline 15 & 370 & 13 & 440 & Tapered & CHS18 & Tabular & & 190 & & 170 \\
\hline 12 & 400 & 16 & 460 & Tapered & CHS17 & Tabular & 40 & 152 & 36 & 135 \\
\hline 53 & 150 & 56 & 190 & Tabular & CHS16 & Tabular & 71 & 62 & 68 & 75 \\
\hline 72 & 30 & 72 & 45 & Tabular & CHS15 & Tabular & 56 & 83 & 53 & 88 \\
\hline 62 & 100 & 74 & 40 & Tabular & CHS14 & Tabular & 70 & 50 & 60 & 95 \\
\hline 40 & 280 & 43 & 240 & Transitional & CHS13 & Tabular & 65 & 54 & 64 & 60 \\
\hline 34 & 355 & 38 & 310 & Tapered & CHS12 & Tabular & 51 & 118 & 49 & 140 \\
\hline 18 & 460 & 21 & 410 & Tapered & CHS11 & Tabular & 50 & 114 & 46 & 126 \\
\hline 21 & 350 & 35 & 370 & Tapered & CHS10 & Tapered & 26 & 300 & 18 & 310 \\
\hline 30 & 420 & 49 & 380 & Tapered & CHS9 & Tabular & 68 & 105 & 60 & 140 \\
\hline 22 & 500 & 48 & 420 & Tapered & CHS8 & Tabular & 66 & 73 & 61 & 120 \\
\hline 21 & 850 & 28 & 620 & Tapered & CHS 7 & Tabular & 63 & 45 & 62 & 45 \\
\hline 20 & 550 & 32 & 550 & Tapered & CHS6 & Tabular & 49 & 52 & 40 & 95 \\
\hline 16 & 790 & 38 & 680 & Tapered & CHS5 & Transitional & 33 & 220 & 29 & 270 \\
\hline 19 & 620 & 38 & 730 & Tapered & CHS4 & Tabular & 52 & 120 & 45 & 150 \\
\hline 14 & 1070 & 18 & 1630 & Tapered & CHS3 & Tabular & 53 & 130 & 50 & 145 \\
\hline 13 & 1100 & 17 & 1820 & Tapered & CHS2 & Tapered & 18 & 810 & 17 & 915 \\
\hline 11 & 1180 & 17 & 1970 & "Tapered" & CHS1 & Transitional & 44 & 215 & 33 & 270 \\
\hline
\end{tabular}

818 Table 2: Classification and metrics of the present-day and restored geometries of each CHS mapped 819 in the south section of the vertical salt wall (figure 10). Measurements were obtained from depthconverted sections. The widths of folding were measured from the inflection points to the tips of each

821 CHS and taper angles by straight lines connecting these two points. 


\begin{tabular}{|c|c|c|c|c|c|c|}
\hline \multicolumn{7}{|c|}{ Vertical Wall Section 2} \\
\hline \multirow[b]{2}{*}{ Taper Angle } & \multirow[b]{2}{*}{ Width of Thinning/Folding zone } & \multicolumn{3}{|c|}{ CLASSIFICATION } & \multicolumn{2}{|r|}{ Depth-Converted } \\
\hline & & LEFT MB & & RIGHT MB & Taper Angle & Width of Thinning/Folding zone \\
\hline- & - & - & CHS18 & - & - & - \\
\hline- & - & - & CHS17 & - & - & - \\
\hline- & - & - & CHS16 & - & - & - \\
\hline- & - & - & CHS15 & - & - & - \\
\hline- & - & - & CHS14 & - & - & - \\
\hline- & - & - & CHS13 & - & - & - \\
\hline- & 470 & Tapered & CHS12 & Tapered & - & 340 \\
\hline 21 & 325 & Tapered & CHS11 & Tabular & 67 & 87 \\
\hline 38 & 240 & Transitional & CHS10 & Tabular & 86 & 25 \\
\hline 42 & 350 & Tapered & CHS9 & Tabular & 82 & 36 \\
\hline 33 & 470 & Tapered & CHS8 & Tabular & 84 & 20 \\
\hline 49 & 450 & Tapered & CHS 7 & Tabular & 77 & 45 \\
\hline 16 & 420 & "Tapered" & CHS6 & Tabular & 80 & 20 \\
\hline- & 540 & Downturn/RV & CHS5 & Tabular & 46 & 200 (transition to shoulder) \\
\hline- & 680 & Downturn/RV & CHS4 & Tabular & 54 & 130 \\
\hline- & 520 & Downturn/RV & CHS3 & Tabular & 53 & 90 \\
\hline- & 370 & Downturn/RV & CHS2 & Tabular & 47 & 160 \\
\hline 11 & 1100 & Tapered & CHS1 & Transitional & 29 & 295 (transition to shoulder \\
\hline
\end{tabular}

823 Table 3: Classification and metrics of the present-day and restored geometries of each CHS mapped

824 in the central section of the vertical salt wall (figure 11). Measurements were obtained from depth-

825 converted sections. The widths of folding were measured from the inflection points to the tips of each

826 CHS and taper angles by straight lines connecting these two points. CHSs 2-5 present distinct

827 downturned and thickened strata in the western minibasin and, thus, are classified as rollover (RV)

828 sequences. Sequences 13-18, defined as CHS further south (Section 1), are not classified as such here

829 as they cover the diapir and, therefore, do not present typical CHS folding and thinning strata. 